NBER WORKING PAPER SERIES

\title{
CLIMATE CHANGE, INSURABILITY OF LARGE-SCALE DISASTERS AND THE EMERGING LIABILITY CHALLENGE
}

\author{
Howard C. Kunreuther \\ Erwann O. Michel-Kerjan \\ Working Paper 12821 \\ http://www.nber.org/papers/w12821
NATIONAL BUREAU OF ECONOMIC RESEARCH
1050 Massachusetts Avenue
Cambridge, MA 02138
January 2007

We would like to thank Carolyn Kousky for her excellent research assistance and Michael Faure and other participants in the Penn Symposium on Climate Change in Philadelphia for very helpful comments. We acknowledge financial support from the National Science Foundation (Award No: 1120617-163123), the Chair on Sustainable Development at the Ecole Polytechnique in Paris and The Wharton Risk Management and Decision Processes Center's Extreme Events Project. The views expressed herein are those of the author(s) and do not necessarily reflect the views of the National Bureau of Economic Research.

(C) 2007 by Howard C. Kunreuther and Erwann O. Michel-Kerjan. All rights reserved. Short sections of text, not to exceed two paragraphs, may be quoted without explicit permission provided that full credit, including $(\subset$ notice, is given to the source. 
Climate Change, Insurability of Large-scale Disasters and the Emerging Liability Challenge Howard C. Kunreuther and Erwann O. Michel-Kerjan

NBER Working Paper No. 12821

January 2007

JEL No. H23,H75,K32

\begin{abstract}
$\underline{\text { ABSTRACT }}$
This paper focuses on the interaction between uncertainty and insurability in the context of some of the risks associated with climate change. It discusses the evolution of insured losses due to weather-related disasters over the past decade, and the key drivers of the sharp increases in both economic and insured catastrophe losses over the past 20 years. In particular we examine the impact of development in hazard-prone areas and of global warming on the potential for catastrophic losses in the future. In this context we discuss the implications for insurance risk capital and the capacity of the insurance industry to handle large-scale events. A key question that needs to be addressed is the factors that determine the insurability of a risk and the extent of coverage offered by the private sector to provide protection against extreme events where there is significant uncertainty surrounding the probability and consequences of a catastrophic loss. We discuss the concepts of insurability by focusing on coverage for natural hazards, such as earthquakes, hurricanes and floods. The paper also focuses on the liability issues associated with global climate change, and possible implications for insurers (including D\&O), given the difficulty in identifying potential defendants, tracing harm to their actions and apportioning damages among them. The paper concludes by suggesting ways that insurers can help mitigate future damages from global climate change by providing premium reductions and rate credits to companies investing in risk-reducing measures.
\end{abstract}

Howard C. Kunreuther

Operations and Information Management

The Wharton School

University of Pennsylvania

Philadelphia, PA 19104-6366

and NBER

kunreuther@wharton.upenn.edu

Erwann O. Michel-Kerjan

The Wharton School - University of Pennsylvania

Center for Risk Management

Jon M. Hunstman Hall - Room 556

3730 Walnut St.

Philadelphia, PA 19104-6340

erwannmk@wharton.upenn.edu 


\section{Introduction}

The World Economic Forum recently stated that climate change was one of the most important global risks that key decision makers will face in the years to come ${ }^{2}$. In the same vein, a report commissioned by the Chancellor of the Exchequer in the United Kingdom echoes this perspective and notes that "climate change presents very serious global risks, and it demands an

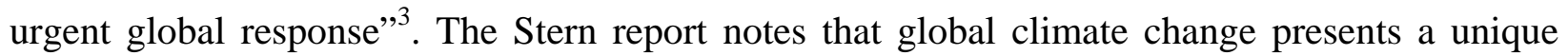
challenge for economics due to the long-time horizons involved, the uncertainty associated with the risk and the unprecedented scale at which one needs to envision such a problem. These points reinforce the feelings expressed by others that we need to address the role of different industrial sectors in reducing the impacts of global warming.

This paper focuses on the role that the insurance sector can play in this regard as well as the challenges insurers and reinsurers face in dealing with the impacts of climate change on their risk management strategies. Indeed, the direct and indirect impacts of firms' activities to limit future emissions of greenhouse gases and adapt in other ways to climate change are likely to have major implications on the insurance sector. In a recent interview, John Coomber, former CEO of Swiss Re, a world reinsurance leader, stated that "climate change is the number one risk in the world ahead of terrorism, demographic change and other global risk scenarios”. ${ }^{4}$ In May 2006 American International Group (AIG), the largest insurer in the United States, issued a statement that "climate change is increasingly recognized as an ongoing, significant global environmental problem with potential risks to the global economy and ecology, and to human health and wellbeing ...."5

Extreme weather-related events (such as hurricane, floods, and ice storms) will impact on the premiums and available coverage for property damage and business interruption losses. It may affect health and life insurance as well. Insurers have also recently begun to pay attention to the liability issues associated with climate change because shareholders have charged some

\footnotetext{
${ }^{2}$ World Economic Forum, Global Risks 2006, (2006), available at www.weforum.com.

3 Nicholas Stern, The Economics of Climate Change. The Stern Review, London: Cabinet Office (2006); forthcoming in January 2007 from Cambridge University Press.

${ }^{4}$ Swiss Re, Climate Risk Group Interview with John Coomber (2006), available at www.swisre.com as of November 1.

5 AIG, AIG's Policy and Programs on Environment and Climate Change, (2006), available at http://media.corporate-ir.net/media_files/irol/76/76115/aig_climate_change_updated.pdf (last accessed December 20, 2006).
} 
companies with failure to prepare for climate-related financial exposures. To the extent that the shareholders take such cases to court, insurers have to defend those firms who have purchased Directors and Officers liability coverage from them. As insurance policies are usually renewed annually, insurers are faced with the problem as to how to set premiums and what coverage to offer in the coming year given our inability to distinguish between random weather patterns and systematic changes in climate in the short run.

The paper is organized as follows. The next section discusses the evolution of catastrophe losses over the past 20 years. In particular we examine the impact of climate change coupled with the development of hazard prone areas on the potential for large losses to insurers in the near future. In this context we discuss the capacity of the insurance industry to handle large-scale disasters without assistance from the public sector. Section 3 discusses the question of attribution, by examining the main drivers of this new dimension of catastrophic losses. While climate change might impact on the intensity and frequency of future hurricanes, the growing concentration of population and industries in high risk areas is largely responsible for the billions of dollars in losses that will result from such an event.

Section 4 discusses the concepts of insurability by focusing on coverage for natural hazards, such as earthquakes, hurricanes and floods, and showing how these extreme events throws into question whether they are insurable by the private sector alone, and if so, under what market conditions? The seven major hurricanes that devastated Florida in 2004 and the Gulf Coast in 2005 have served as a wake-up call to not only insurers and reinsurers but to other stakeholders such as modeling firms that have developed catastrophe models for quantifying insurers' and reinsurers' exposure, rating agencies that have modified their rating methodologies and imposed more stringent conditions on insurers and reinsurers, and investors who now require a higher return on equity to reflect higher volatility of insurers' portfolio due to uncertainty associated with the new scale of extreme events. Section 5 demonstrates how these stakeholders are modifying the frontier of the insurability of catastrophic risks.

Section 6 focuses on another challenge that will face the insurance sector in the coming years: the liability issues associated with global climate change given the difficulty in identifying potential defendants, tracing harm caused by their actions and apportioning damages between them. We suggest ways that insurers can help mitigate future damages from global climate change by providing premium reductions and rate credits to companies that have taken actions 
that produce short-run tangible benefits and have a long-run positive impact on global climate change. Section 7 provides a brief summary of our findings and issues a call for more systematic collection of data.

\section{Changes in Extreme Weather-Related Events}

Catastrophes have had a more devastating impact on insurers over the past 15 years than in its entire history. Between 1970 and the mid-1980s annual insured losses from natural disasters (including forest fires) were in the \$3 to 4 billion range. The insured losses from Hurricane Hugo that made landfall in Charleston, South Carolina on September 22, 1989 exceeded \$4 billion (1989 prices). It was the first natural disaster to inflict more than one billion dollars of insured losses in the U.S. In the 1990s, the scale of insured losses from major natural disasters changed radically: \$17 billion in 1991, greater than \$30 billion in 1992 with \$20 billion from Hurricane Andrew alone, more than \$20 billion in 1994 with \$18 billion from the Northridge earthquake, and \$25 billion in 1999 mainly due to major storms and flood in Europe.

A new record was reached in 2004 with total financial losses of $\$ 120$ billion from natural disasters throughout the world; $\$ 49$ billion of these losses were covered by insurance ${ }^{6}$. This upward trend is continuing. In 2005, insured losses from Hurricane Katrina are estimated at \$45 billion in insured losses. World wide major catastrophes in 2005 inflicted $\$ 230$ billion in economic damage, $\$ 83$ billion of which was covered by insurance. This is twice as much damage as in 2004. Figure 1 depicts the upward trend in worldwide insured losses from catastrophes between 1970 and 2005 (in 2005 indexed prices) ${ }^{7}$.

\footnotetext{
${ }^{6}$ Swiss Re, Natural catastrophes and man-made disaster in 2004: more than 300,000 fatalities, record insured losses, 2005 Sigma no. 1 (2005).

${ }^{7}$ There has been a growing literature studying the evolution of insured losses due to major catastrophes in the world. While total figures differ from one source to another, mainly due to the definition of a catastrophe, all reach the same conclusion. For example natural disasters inflicting loss above 70 million dollars of insured loss are considered a major catastrophe by Swiss Re (we use this threshold in Figure 1); Munich Re considers a higher threshold. As a result, most figures used in the literature regarding the evolution of catastrophe loss actually underestimate the real effect on insurers. In the US, Property Claim Services define "catastrophe" as an event that inflicts only insured loss above \$25 million; smaller events (even repeated) are not included in PCS catastrophe database.
} 


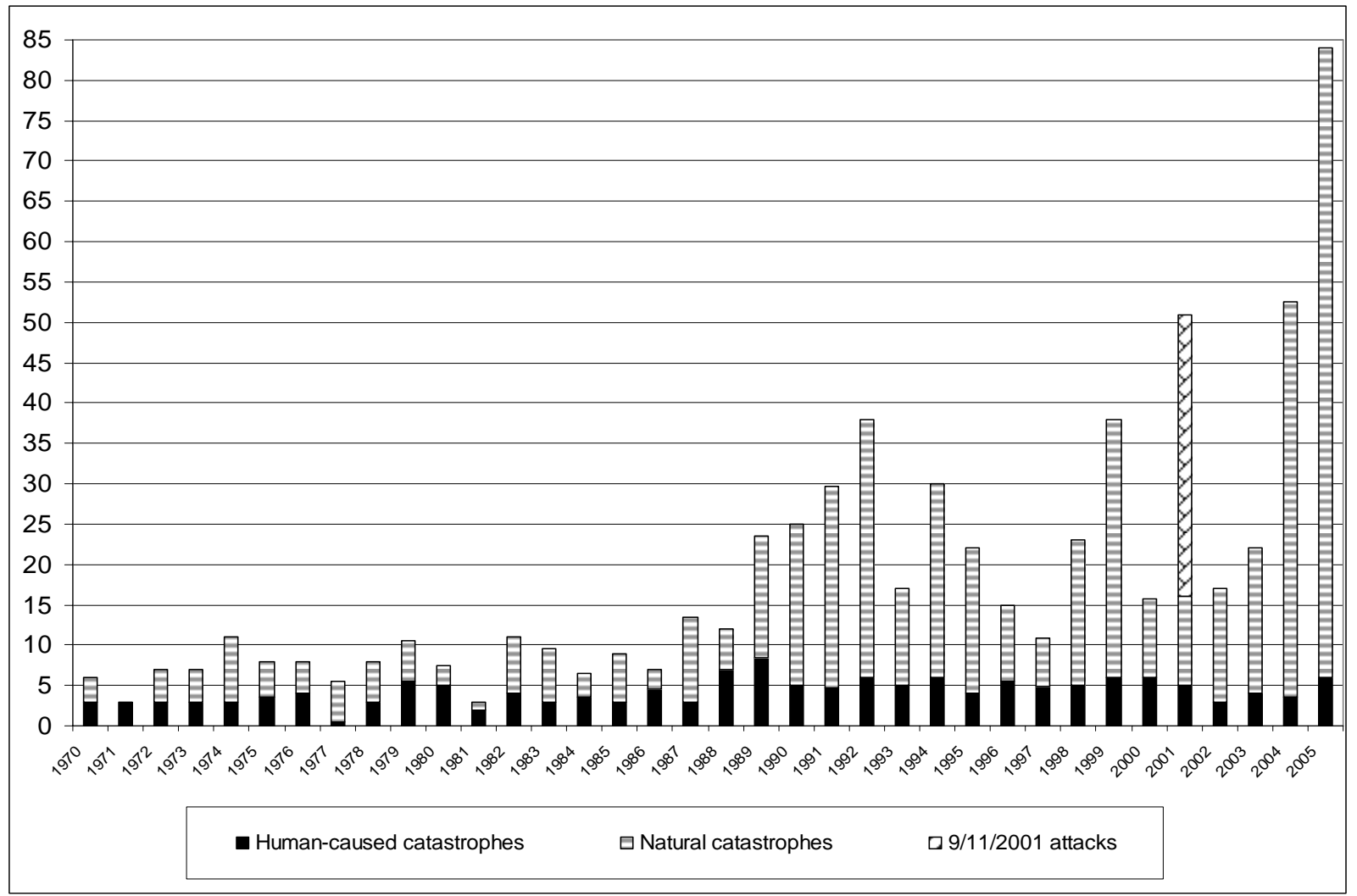

Figure 1. Worldwide Evolution of Catastrophe Insured Losses, 1970-2005

(9/11/2001: all lines, including property and business interruption (BI); in U.S.\$ billon indexed to 2005)

Sources: Wharton Risk Center with data from Swiss Re and Insurance Information Institute

Table 1 shows the 20 most costly catastrophes for the insurance sector over the past 35 years in 2005 dollars. With the exception of the terrorist attacks of September 11, 2001, the remaining 19 most costly events were natural disasters ${ }^{8}$. Among these natural disasters more than 80\% were weather-related events: hurricanes and typhoons, storms, and floods with nearly three quarters of the claims emanating from the United States. The new era we have now entered is best illustrated by data showing that the 20 most costly events over this 35-year period, 10 occurred during the past 5 years (in constant prices).

In the 1990s, the insured losses from Hurricane Andrew in 1992 and the Northridge earthquake in 1994 led insurers and reinsurers to pay much more attention to the catastrophic

\footnotetext{
${ }^{8}$ The two most costly industrial catastrophes in regards to insurance claims over this 35-year period are the explosion of the oil offshore platform Piper Alfa in the U.K. in July 1988, which cost about \$3.2bn to insurers, and the explosion of a petrochemical plant in the U.S. in October 1989 that inflicted insured damage of \$2bn (2004 indexed price).
} 
potential of natural disasters. These two events, considered the first two "super-catastrophes", caused insurers to reflect on what constitutes an insurable risk. To assist them in making this determination, many firms began utilizing catastrophe models to estimate the likelihood and consequences to their insured portfolios from specific disasters in hazard-prone areas ${ }^{9}$.

Table 1.1. The 20 Most Costly Insured Catastrophes in the World, 1970-2005 (in italics those that occurred between 2001 and 2005)

\begin{tabular}{|l|l|l|l|l|l|}
\hline Rank & $\begin{array}{c}\text { U.S.\$ } \\
\text { billion } \\
\text { (indexed to 2005) }\end{array}$ & \multicolumn{1}{|c|}{ Event } & $\begin{array}{c}\text { Victims } \\
\text { (Dead or } \\
\text { missing) }\end{array}$ & Year & Area of primary damage \\
\hline $\mathbf{1}$ & $\mathbf{4 5}$ & Hurricane Katrina & 1,326 & 2005 & USA, Gulf of Mexico et al \\
\hline $\mathbf{2}$ & $\mathbf{3 5}$ & 9/11 Attacks & 3,025 & 2001 & USA \\
\hline $\mathbf{3}$ & $\mathbf{2 2 . 3}$ & Hurricane Andrew & 43 & 1992 & USA, Bahamas \\
\hline $\mathbf{4}$ & $\mathbf{1 8 . 5}$ & Northridge Quake & 61 & 1994 & USA \\
\hline $\mathbf{5}$ & $\mathbf{1 1 . 7}$ & Hurricane Ivan & 124 & 2004 & USA, Caribbean et al \\
\hline $\mathbf{6}$ & $\mathbf{1 0 . 3}$ & Hurricane Wilma & 35 & 2005 & USA, Gulf of Mexico et al \\
\hline $\mathbf{7}$ & $\mathbf{8 . 3}$ & Hurricane Charley & 24 & 2004 & USA, Caribbean et all \\
\hline $\mathbf{8}$ & $\mathbf{8 . 1}$ & Typhoon Mireille & 51 & 1991 & Japan \\
\hline $\mathbf{9}$ & $\mathbf{6 . 9}$ & Winterstorm Daria & 95 & 1990 & France, UK et al \\
\hline $\mathbf{1 0}$ & $\mathbf{6 . 8}$ & Winterstorm Lothar & 110 & 1999 & France, Switzerland et al \\
\hline $\mathbf{1 1}$ & $\mathbf{6 . 6}$ & Hurricane Hugo & 71 & 1989 & Puerto Rico, USA et al \\
\hline $\mathbf{1 2}$ & $\mathbf{5 . 2}$ & Hurricane Frances & 38 & 2004 & USA, Bahamas \\
\hline $\mathbf{1 3}$ & $\mathbf{5 . 2}$ & Storms and floods & 22 & 1987 & France, UK et al \\
\hline $\mathbf{1 4}$ & $\mathbf{5 . 0}$ & Hurricane Rita & 34 & 2005 & USA, Gulf of Mexico et al \\
\hline $\mathbf{1 5}$ & $\mathbf{4 . 8}$ & Winterstorm Vivian & 64 & 1990 & Western/Central Europe \\
\hline $\mathbf{1 6}$ & $\mathbf{4 . 7}$ & Typhoon Bart & 26 & 1999 & Japan \\
\hline $\mathbf{1 7}$ & $\mathbf{4 . 2}$ & Hurricane Georges & 600 & 1998 & USA, Caribbean \\
\hline $\mathbf{1 8}$ & $\mathbf{4 . 1}$ & Hurricane Jeanne & 3,034 & 2004 & USA, Caribbean et al \\
\hline $\mathbf{1 9}$ & $\mathbf{3 . 7}$ & Typhoon Songda & 45 & 2004 & Japan, South Korea \\
\hline $\mathbf{2 0}$ & $\mathbf{3 . 5}$ & Tropical Storm Alison & 41 & 2001 & USA \\
\hline
\end{tabular}

Sources: Wharton Risk Center with data from Swiss Re and Insurance Information Institute

\section{Insured versus Economic Impact}

Insurance does not decrease the global losses from an untoward event but rather spreads its financial impact by enabling those at risk to pay a relatively small premium so they can be protected against a large loss that has a small chance of occurring. Hence insured losses reflect only a part of the total economic damage inflicted by a disaster. By definition the ratio of economic losses to insured losses (L/I) will be very high when there is a limited insurance market, as is often the case in developing countries. For example, in 1996 major floods in China inflicted about $\$ 24$ billion of economic loss, less than $\$ 500$ million of which was covered by insurance, leading to an L/I ratio greater than 50. Two years later, in 1998, other floods in China

\footnotetext{
${ }^{9}$ Patricia Grossi and Howard Kunreuther (eds.), Catastrophe Modeling: A New Approach to Managing Risk (2005).
} 
cost about $\$ 30$ billion in direct economic loss, with only $\$ 1$ billion was covered by insurance so that the L/I ratio was 30. High L/I ratios have also been observed in industrialized countries where there are no minimum insurance requirements. For example, the large-scale earthquake that devastated Kobe, Japan in 1995 cost \$110 billion (L), only \$3 billion of which was covered by insurance (I).

Traditionally, there has been a much lower L/I ratio in the U.S. market ranging, from 2-4, principally due to required insurance coverage by banks and financial institutions as a condition for a mortgage and the use of effective mitigation measures for reducing losses from natural disasters. In the cases of Hurricane Andrew and the Northridge earthquake the L/I ratio was about 1.5 (26/17) and 2.8 (44/15.5), with both L and I specified in billions of dollars. For Hurricane Katrina, the ratio is in the $3-4$ range $[(150-170) / 45)^{10}$.

Figure 2 compares economic loss and insured losses for "great natural disasters” from 1960-2004. Economic losses follow the same increasing trend described earlier for insured losses. The grey zones in the graph represent the average annual economic loss by decade (in 2004 prices). A comparison of these economic losses over time reveals a huge increase: \$44.9 billion (1950-59), \$80.5 billion (1960-69), \$147.6 billion (1970-80), \$228 billion (1980-89) and $\$ 703.6$ billion (1990-99). While the economic losses during the first four years of the $21^{\text {st }}$ century (2000-2003) were less severe than loss in previous years, 2004 inflicted about \$113 billion of dollars in economic loss, the second most devastating year of this 44 -year period ${ }^{11}$. And 2005 alone inflicted twice as much.

\footnotetext{
${ }^{10}$ Estimations for total economic losses due to Hurricane Katrina are still not definitive.

${ }^{11}$ Munich Re, Annual Review: Natural Catastrophes 2004, Knowledge series (2005).
} 


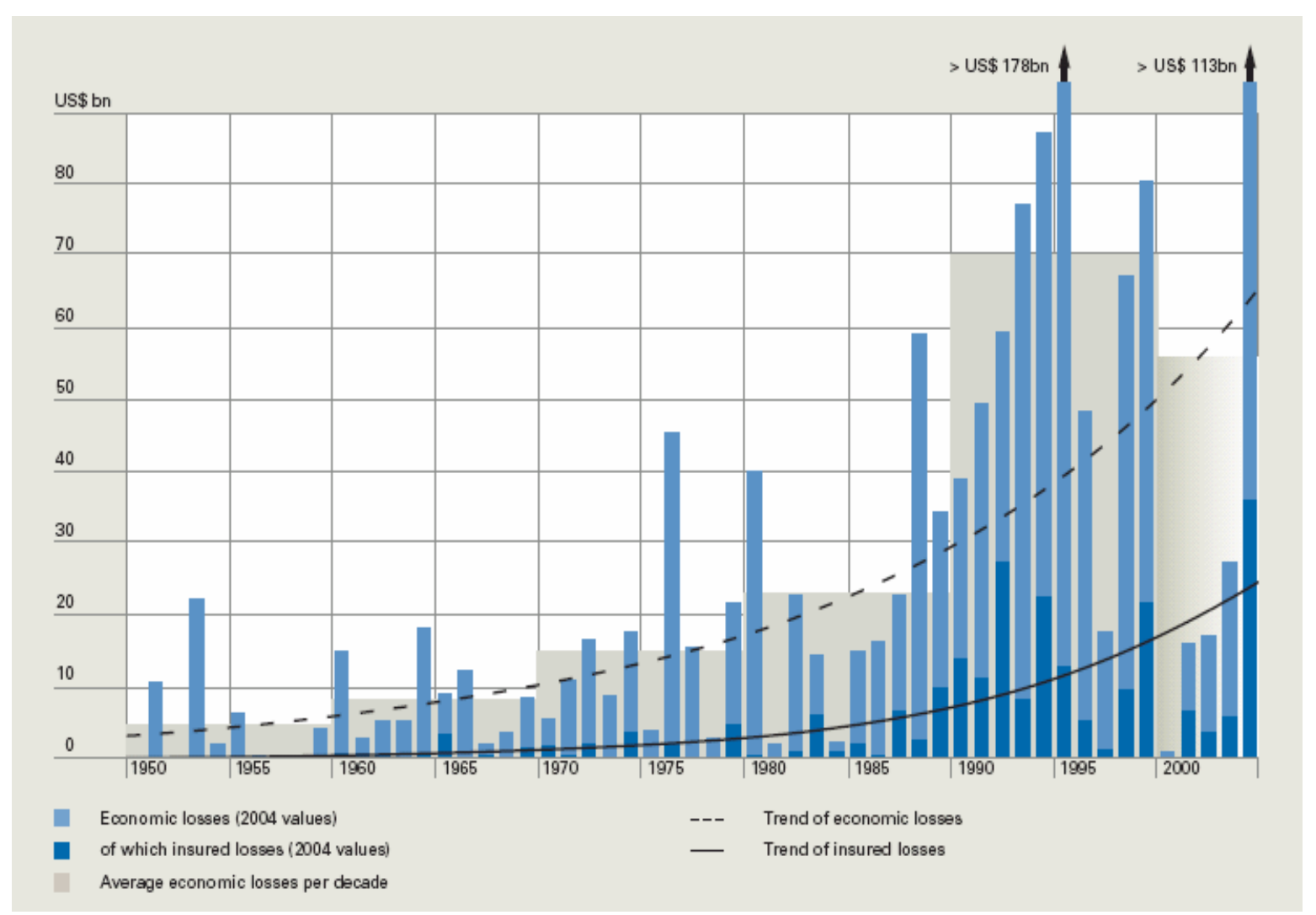

Figure 2. Evolution of “Great Natural Catastrophe” 1960-2004. Economic versus Insured Impact ${ }^{12}$

Sources: Munich Re (2005-infra)

\section{Economic versus Human Impacts}

Fatalities often do not factor into insurance loss rankings. The correlation between insured losses and fatalities is even less clear than the relationship between insured and economic losses. As a large number of natural disasters occur in the developing world or in poor areas of developed countries where there is limited insurance in place, one needs to pay attention to fatality factors independent of their impact on insured losses. For example, the tsunami that devastated South Asia in December 2004 cost the insurance industry about \$5 billion primarily from losses to tourism activities, but the disaster killed over 280,000 people and constitutes the second most deadly natural disaster event over the past 100 years (a storm and flood killed

\footnotetext{
${ }^{12}$ As discussed above, figures differ from one source to another. Munich Re and Swiss Re, the two leading reinsurers in the world, do not use the same definition. Typically, Munich Re's estimation are lower than Swiss Re, the former selecting only the very large natural catastrophe, when the latter being less restrictive in its definition. These differences can be very important. For example, when Munich Re estimates insured loss at about $\$ 35$ billion in 2004, Swiss Re’s estimation is $\$ 49$ billion. And again, both these estimation underestimate the real total cost of natural disasters. However, they also constitutes the most extensive (both in time and scale) estimation of that sort.
} 
300,000 people in 1972 in Bangladesh). More generally, the most deadly natural disasters from the point of view of lives lost occur in developing countries. Between 1970 and 2004, 20 catastrophes each killed over 10,000 people. All of them but one (the Izmir earthquake in Turkey in 1999) occurred in non-OECD countries. ${ }^{13}$

\section{The Question of Attribution: A Focus on Weather-Related Events}

In the preceding section, we discussed natural disasters without differentiating between weather-related events (e.g., storms, floods, droughts, heat waves, cold, and frost) and non weather-related events (e.g., earthquakes). With respect to the relationship between climate change and insurance, it is important to focus on weather-related events. ${ }^{14}$

Over the period between 1970 and 2004, storms and floods have been responsible for over $\mathbf{9 0 \%}$ of the total economic costs of extreme weather-related events. Storms (hurricanes in the US region, typhoons in the Japan region and windstorms in Europe) contribute to over $75 \%$ of inured losses. Floods represent about 10\%. According to a recent study by the Association of British Insurers (ABI), every year since 1990, there have been at least 20 weather-related events that are severe enough to be classified by leading reinsurers as significant catastrophes. In contrast between 1970 and 1990 only three years experienced more than 20 such significant catastrophes. In constant prices (2004), insured losses due to weather-related events averaged \$3 billion annually between 1970 and 1990 and then increased significantly to $\$ 16$ billion annually between 1990 and $2004^{15}$. In 2005, 99.7\% of all catastrophe losses worldwide were due to weather-related events (Mills and Lecomte, 2006) ${ }^{16}$.

This raises the question as to what are the key drivers of the increase in these losses? More specifically, what role did socio-economic factors play in affecting this trend? How is a change in climate likely to affect the number and severity of catastrophes in the future?

\footnotetext{
${ }^{13}$ Swiss Re, Natural catastrophes and man-made disasters in 2004, 1/2005 Sigma (2005).

${ }^{14}$ Earthquakes are a major source of catastrophes as well. While not related to climate change, they can also seriously affect insurance capacity. A major earthquake in California today would be economically devastating and have a large impact on how the insurance industry could handle future catastrophes, including weather-related ones. A major earthquake in Tokyo could inflict economic losses at a trillion dollar level, with critical impacts on financial markets worldwide, and even lead to recession.

${ }^{15}$ Association of British Insurers (ABI), Financial Risks of Climate Change, June (2005).

${ }^{16}$ Evan Mills and Eugene Lecomte, From Risk To Opportunity: How Insurers Can Proactively and Profitably Manage Climate Change, CERES (2006).
} 


\section{Impact of Socio-Economic Factors on Increased Losses}

There are at least two principal socio-economic factors that directly influence the level of economic losses due to weather-related events: degree of urbanization and value at risk.

In 19502.5 billion people, approximately 30\% of the world's population, lived in cities. In 2000, about $50 \%$ of the world's population (6 billion) resided in urban areas. Projections by the United Nations show that by 2025, that figure will have increased to $60 \%$ based on a world population estimate of 8.3 billion people. A direct consequence of this movement is the increasing number of so-called mega-cities with populations greater than 10 million. In 1950, New York City was the only mega-city. In 1990, there were 12 such cities. By 2015 there are expected to be 26 such cities, several of which are located in high natural hazard prone areas, with Tokyo leading the way with an estimated 29 million inhabitants ${ }^{17}$ followed by Shanghai (estimated at 18 million), New York (estimated at 17.6 million), and Los Angeles (estimated at 14.2 million inhabitants).

In hazard prone areas, this urbanization and increase of population also translates into increased concentration of exposure. The development of Florida as a home for retirees is an example. The population of Florida has increased significantly over the past 50 years: 2.8 million inhabitants in 1950, 6.8 million in 1970, 13 million in 1990, and a projected 19.3 million population in 2010 (almost a 700\% increase since 1950) ${ }^{18}$.

The increase in the value exposed to natural hazards amplifies the potential for severe economic and insured losses. If Hurricane Andrew had occurred in 2002 rather than 1992, it would have inflicted twice the economic losses, due principally to increasing coastal development and rising asset values in Miami/Dade County and adjoining coastal areas in Florida affected by the storm $^{19}$.

Florida also has a very high density of insurance coverage with almost all houses insured against windstorms by private insurers and about one third of residences insured against floods

\footnotetext{
17 Although not weather-related, the experience of the Kobe earthquake in 1995 highlights the potential for real cataclysms in the region. An even bigger quake in Greater Tokyo could inflict economic loss in the range of \$1-to-3 trillion.

${ }^{18}$ Sources: U.S. Bureau of the Census.

19 Andrew Dlugolecki, Thoughts about the Impact of climate change on insurance claims, in P. Höppe and R. Pielke (eds.), Report of the Workshop on Climate Change and Disaster Losses, May 25-26, (2006).
} 
under the U.S. National Flood Insurance Program (NFIP) ${ }^{20}$, according to a study undertaken by Munich $\mathrm{Re}^{21}$. The modeling firm AIR Worldwide estimates that nearly $80 \%$ of insured assets in Florida today are located near the coasts, the high risk area in the state. In real terms this represents a huge amount of exposure: \$1.9 trillion of insured exposure located in coastal areas (\$1.4 trillion of commercial exposure and $\$ 900$ billion of residential exposure) ${ }^{22}$. Insurance density is thus another critical socio-economic factor to consider when evaluating the evolution of insured loss due to weather-related catastrophes.

Another example in the U.S. relates to industrialized development in the Gulf of Mexico. The first off-shore oil platform was built for water depths higher than 100 meters in the 1960s. Today there are numerous such platforms in the Gulf of Mexico and North Sea, two regions highly exposed to major storms ${ }^{23}$. Indeed, $75 \%$ of the 4,000 platforms administered by the Minerals Management Service were in the path of Hurricanes Katrina and Rita which destroyed a large number of them. Hurricane Katrina shut down an estimated $95 \%$ of crude production and 88\% of natural gas output in the Gulf of Mexico, inflicting major business interruption insured losses. According to the U.S. Department of Energy, two months after Katrina made landfall as a category 3 hurricane (August 29, 2005), the shortfall of oil production was still 1 million barrel a day, compared to 200,000 barrels two months after Hurricane Ivan that had hit one year earlier. It will take months before we recover full capacity. This example raises the question as to the economic cost and size of insurance claims payments related to business interruption ${ }^{24}$.

These factors will continue to have a major impact on the level of insured losses from natural catastrophes. There is a need for a more granular approach to better understand trends in specific areas and the opportunities to reduce losses through mitigation measures tailored to these properties. Quantifying each of these factors -increased urbanization, inflation, increased value at risk, as well as higher density of insurance coverage - at a local level remains a challenge.

\footnotetext{
${ }^{20}$ The NFIP is a public insurance program created in 1968, where insurers play the role of intermediaries between the policyholders and the federal government. Following Hurricane Katrina, the program had to borrow $\$ 20$ billion from the federal government in 2006 to meet its claims. Congress is considering modifying the program substantially.

${ }^{21}$ Munich Re, Topics 2000. Natural Catastrophes - The Current Position, Special millennium issue (2000).

${ }^{22}$ Robert Hartwig, Hurricane Season of 2005: Impacts on US P/C Insurance Markets in 2006 \& Beyond, (2006).

${ }^{23}$ At a state level, one estimates insured exposure in coastal areas of Texas to be nearly $\$ 750 \mathrm{bn}$ today.

${ }^{24}$ It is fair to say that the impacts on the energy infrastructure would have been much more devastating had a major hurricane hit a city like Houston, Texas. This scenario would result in large-scale property and business interruption losses for oil/chemical industry firms and their insurers.
} 


\section{Likelihood versus Intensity}

We now turn to the second question: How is a change in climate likely to affect the number and severity of weather-related catastrophes? One of the expected effects of global warming will be an increase in hurricane intensity. This has been predicted by theory and modeling and substantiated by empirical data. Higher ocean temperatures lead to an exponentially higher evaporation rate in the atmosphere which increases the intensity of cyclones and precipitation. Emanuel $(2005)^{25}$ introduces an index of potential destructiveness of hurricanes based on the total dissipation power over the lifetime of the storm. He shows a large increase in power dissipation over the past 30 years and concludes that this increase may be due to the fact that storms have become more intense, on the average, and/or have survived longer at high intensity. His study also shows that the annual average storm peak wind speed over the North Atlantic and eastern and western North Pacific have increased by 50\% over the past 30 years.

Another paper by Webster et al. ${ }^{26}$ published a few weeks later indicates that the number of Category 4 and 5 hurricanes worldwide has nearly doubled over the past 35 years. ${ }^{27}$ In the 1970s, there was an average of about ten Category 4 and 5 hurricanes per year globally. Since 1990, the number of Category 4 and 5 hurricanes has averaged 18 per year. Focusing only on the North Atlantic (Atlantic-Caribbean-Gulf of Mexico), Category 4 \& 5 hurricanes have increased from 16 in the period of 1975-89 to 25 in the period of 1990-2004 (a 56 percent increase). The Webster et al. study concludes that "global data indicate a 30-year trend toward more frequent and intense hurricanes.... This trend is not inconsistent with recent climate model simulations that a doubling of $\mathrm{CO}_{2}$ may increase the frequency of the most intense cyclones, although attribution of the 30-year trends to global warming would require a longer global data record and, especially, a deeper understanding of the role of hurricanes in the general circulation of the atmosphere and ocean, even in the present climate state”. This significant increase in observed

\footnotetext{
${ }^{25}$ Kerry Emanuel, Increasing destructiveness of tropical cyclones over the past 30 years, 436 NATURE at 686, (2005).

${ }^{26}$ P. Webster, G. Holland, J. Curry and H.-R. Chang, Changes in Tropical Cyclone Number, Duration, and Intensity in a Warming Environment, 309 SCIENCE at 1844, (2005).

${ }^{27}$ Category 4 hurricanes have sustained winds from 131 to 155 miles per hour; Category 5 systems, such as Hurricane Katrina at its peak over the Gulf of Mexico, have sustained winds of 156 mph or more.
} 
tropical cyclone intensities, linked to warming sea surface temperatures that may be associated with global warming has been shown in another study published recently ${ }^{28}$.

But this is not to say that there is a consensus by scientists on this issue ${ }^{29}$. In a perspective article published this summer in Science, Landsea et al. point out that subjective measurements and variable procedures make existing tropical cyclone databases insufficiently reliable to detect trends in the frequency of extreme cyclones. They note that "modeling and theoretical studies suggest only small anthropogenic changes to tropical cyclone intensity several decades into the future [an increase on the order of $\sim 5 \%$ near the end of the 21st century] ${ }^{30}$.

This conclusion is reinforced in a recent summary of articles on global climate change by Patrick Michaels, past president of the American Association of State Climatologists. He notes that all studies of hurricane activity that claim a link between human causation and the recent spate of hurricanes must also account for the equally active period around the mid $20^{\text {th }}$ century. Studies using data from 1970 on begin at a cool point in the hemisphere's temperature history and hence may draw erroneous conclusions regarding global climate change and hurricane activity $^{31}$.

The current debate in the scientific community regarding changes in the frequency and intensity of hurricanes and its relationship to global climate change is likely to be with us for a long time to come. The results to date do, of course, raise issues for the insurance industry to the extent that an increase in the number of major hurricanes over a shorter period of time is likely to translate into a higher number hitting the coasts ${ }^{32}$. As discussed above, they are more likely to damage a much larger number of residences and commercial buildings today than if a similar hurricane had occurred in the 1940s. This raises the question of insurability of major hurricanes, in particular, and large-scale disasters in general, a topic to which we now turn.

\footnotetext{
${ }^{28}$ C. Hoyos, P., Agudelo, P., Webster, J., A. Curry, Deconvolution of the Factors Contributing to the Increase in Global Hurricane Intensity, 312 SCIENCE at 94 (2006).

${ }^{29}$ See, for instance, the exchange between Roger Pielke, Jr., Christopher W. Landsea and Kerry Emanuel in 438 NAture, Nos. 22 and 29 (2005), J. Chan Comment on "Changes in Tropical Cyclone Number, Duration, and Intensity in a Warming Environment, 311 Science at 1713 (2006), and P. J. Webster, J. A. Curry, J. Liu, G. J. Holland, Response to Comment on "Changes in Tropical Cyclone Number, Duration, and Intensity in a Warming Environment", 311 SCIENCE at 1713 (2006).

${ }^{30}$ Christopher W. Landsea, Bruce A. Harper, Karl Hoarau, John A. Knaff, Can We Detect Trends in Extreme Tropical Cyclones?, 313 SCIENCE at 452 (2006).

${ }^{31}$ P. Michaels, Is the Sky Really Falling? A Review of Recent Global Warming Scare Stories, 576 PoLICY ANALYSIS (2006).

${ }^{32}$ For more discussion on this issue see Mills, E. Insurance in a Climate of Change, 308 SCIENCE at 1040 (2005) and P. Höppe and R. Pielke (eds), Report of the Workshop on Climate Change and Disaster Losses, May 25-26, (2006).
} 


\section{Dealing with Uncertain Catastrophic Loss: The Insurability Challenge}

Hurricane Andrew in 1992 and the Northridge Earthquake in 1994 forced the insurance industry to reconsider its approach to deal with catastrophes ${ }^{33}$. The dramatic increase in economic and insured losses due to weather-related events in the ensuing 10 years culminating with the seven major hurricanes that hit the U.S. in 2004 and 2005 and inflicted over $\$ 90$ billion insured losses. Today insurers and reinsurers are reexamining their ability to provide protection against wind damage from hurricanes and are asking the question as to whether these events are insurable, and at what price.

To understand the concept of insurability consider a standard insurance policy whereby premiums are paid at the start of a given time period to cover losses during this interval (usually a year). Two conditions must be met before insurance providers are willing to offer coverage against an uncertain event. The first is the ability to identify and quantify, or estimate at least partially, the chances of the event occurring and the extent of losses likely to be incurred. The second condition is the ability to set premiums for each potential customer or class of customers.

If both conditions are satisfied, a risk is considered to be insurable. But it still may not be profitable. In other words, it may be impossible to specify a rate for which there is sufficient demand and incoming revenue to cover the development, marketing, operating and claims processing costs of the insurer and yield a net positive profit over a pre-specified time horizon. In such cases, the insurer will opt not to offer coverage against this risk.

The above two conditions are relevant to the climate change debate. To be clear here, insurance does not cover climate change, but a series of pre-specified perils and causes some of which could occur as a result of climate change, or be affected by it.

\section{Determining Premiums and Coverage}

Basic Concepts -- The insurance business, like any other business, has its own vocabulary. A policyholder is a person who has purchased insurance. A premium is the amount that a policyholder pays in return for the promise of a payment from the insurer should he suffer a loss covered by his policy. A claim means that the policyholder is seeking to recover financial payments from the insurer for damage covered by the policy. A claim will not result in a

\footnotetext{
${ }^{33}$ Patricia Grossi and Howard Kunreuther (eds.), Catastrophe Modeling: A New Approach to Managing Risk (2005).
} 
payment by the insurer if the amount of the insured's financial loss is below the stated deductible (i.e. the amount or proportion of an insured loss that the policyholder agrees to pay before any recovery from the insurer) or if the loss is subject to policy exclusions (e.g., war or insurrection). However, insurers will still incur expenses in investigating the claim.

Insurer capital represents the net worth of the company (assets minus liabilities). Capital enables the insurer to pay any losses above those that were expected. It serves as a safety net to support the risk that an insurer takes on by writing insurance and helps ensure that the insurer will be able to honor its contracts. As such, it supports the personal safety nets of homeowners, business owners, workers, dependents of heads of households and others who rely on insurance to provide financial compensation to rebuild their lives and businesses after covered losses occur. Insurer capital is traditionally referred to as policyholders'surplus; it is an essential component supporting the insurance promise. The cost of that capital is an insurer expense that must be considered in pricing insurance, along with expected losses, sales and administrative expenses for policies written ${ }^{34}$.

The capital needed by an insurer varies directly with the risk that the insurer assumes. If an insurer wishes to take on more risk, it must have capital to support the additional coverage it offers against that risk. Insurance regulators and rating agencies devote significant efforts towards evaluating the adequacy of the insurer's capital relative to the amount and types of risk they are taking on to assure policyholders that they will be able to recoup their claims following a large-scale disaster. Holding an adequate level of capital is critical to the continued viability of an insurer.

Insurance markets function best when the losses associated with a particular risk are independent of each other and the insurer has accurate information on the likelihood of the relevant events occurring and the resulting damage. By selling a large number of policies for a given a risk, the insurer is likely to have an accurate estimate of claim payments it expects to make during a given period of time. To illustrate this point with a simple example, consider an insurer who provides fire insurance to a set of identical homes each valued at $\$ 100,000$. Using historical data, the insurer estimates that there is a 1/1000 chance that each home will be

\footnotetext{
${ }^{34}$ Consider, for example, insurance for property damage caused by hurricanes. An insurer's expected losses are relatively low, because in a typical year, the policyholder will not suffer a hurricane loss. However, it is possible that losses will be quite high - far in excess of those expected at the time policies are priced. In the event of a serious hurricane, a substantial portion of the loss must be paid from insurer capital. For terrorism coverage, maximum losses are extremely high relative to expected losses, so the capital issue is critical.
} 
destroyed by fire next year. In this case the expected annual loss for each home from fire would be $\$ 100$ (i.e. $1 / 1000$ x $\$ 100,000)$.

If the insurer issued only a single policy to cover the full loss from a fire, then there would be a variance of approximately $\$ 100$ associated with its expected annual loss ${ }^{35}$. As the number of policies issued, $n$, increases, the variance of the expected annual loss, or the mean loss per policy, decreases in proportion to $n$. Thus, if $n=10$, the variance of the mean loss will be approximately $\$ 10$. When $n=100$ the variance decreases to $\$ 1$, and with $n=1,000$ the variance is $\$ 0.10$. It is thus not necessary to issue a very large number of policies to reduce significantly the variability of expected annual losses per policy if the risks are independent. This model of insurance works well for risks such as fire, automobile and loss of life because they satisfy the assumptions of independence and the ability to estimate probabilities and losses. Risks associated with climate change do not satisfy the above conditions, so they are more problematic to insure.

Risk, Ambiguity, Uncertainty and Ignorance -- An important element when it comes to climate change and insurance is the distinction between "risk" and "uncertainty". An event is considered to be risky when the probabilities that certain states will occur in the future are precisely known, e.g. in a fair roulette game. In contrast, a risk is uncertain when the probabilities are not precisely known. Examples are the likelihood of a terrorist attack in New York City or the chance of a Category 5 hurricane hitting the coast of Florida in the next 12 months.

The term uncertainty is often used interchangeably with the term ambiguity which implies that there are vague beliefs about the likelihood of events occurring. If people are not able to form any beliefs about probabilities, this special case is termed complete ignorance ${ }^{36}$. Similar distinctions can be made relative to the outcome. Based on our knowledge today the likelihood and consequences of weather-related events associated with climate change are characterized by high levels of uncertainty.

\footnotetext{
35 The variance for a single loss $L$ with probability $p$ is $L p(1-p)$. If $L=\$ 100,000$ and $p=1 / 1,000$, then $L p(1-p)=$ $\$ 100,000(1 / 1,000)(999 / 1,000)$, or $\$ 99.90$.

${ }^{36}$ Camerer, C. and M. Weber Recent, developments in modeling preferences: Uncertainty and ambiguity, 5 JOURNAL OF RISK AND UNCERTAINTY at 325 (1992).
} 
Modeling Catastrophe -- Before insurance providers are willing to offer coverage against an uncertain event they feel they must be able to identify and quantify, or at least partially estimate, the chances of the event occurring and the extent of losses likely to be incurred. Such estimates can be based on past data (e.g., loss history of the insurer's portfolio of policyholders, loss history in a specific region) coupled with data on what experts know about a particular risk through the use of catastrophe models.

The four basic components of a catastrophe model are: hazard, inventory, vulnerability and loss, as depicted in Figure 3, and are illustrated for a natural hazard such as a hurricane. First, the model determines the risk of the hazard phenomenon, which in the case of a hurricane is characterized by its projected path and wind speed. Next, the model characterizes the inventory (or portfolio) of properties at risk as accurately as possible This is done by first assigning geographic coordinates to a property and then determining how many structures in the insurer's portfolio are at risk from hurricanes of different wind speeds and projected paths. For each property's location in spatial terms, other factors that characterize the inventory at risk are the construction type, the number of stories in the structure, and its age.

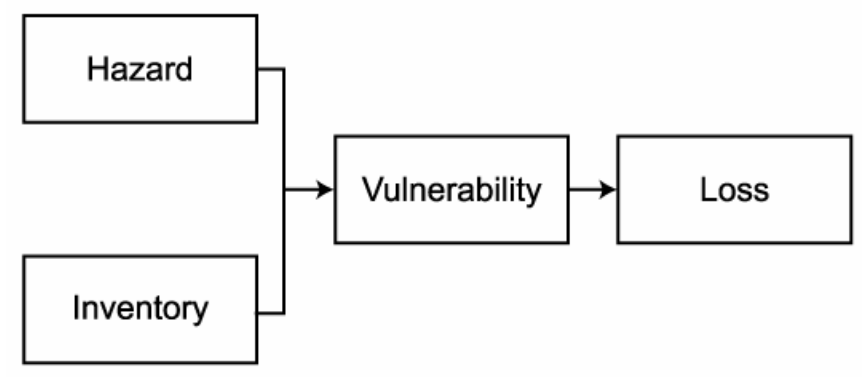

Figure 3. Structure of Catastrophe Models

The hazard and inventory modules enable one to calculate the vulnerability or susceptibility to damage of the structures at risk. In essence, this step in the catastrophe model quantifies the physical impact of the natural hazard phenomenon on the property at risk. How this vulnerability is quantified differs from model to model. Based on this measure of vulnerability, the loss to the property inventory is evaluated. In a catastrophe model, loss is characterized as direct or indirect in nature. Direct losses include the cost to repair and/or replace a structure, which has to anticipate the increase in cost of material and workforce due to the 
demand surge in the aftermath of a major disaster. Indirect losses include business interruption impacts and relocation costs of residents forced to evacuate their homes.

Exceedance Probability Curves -- Based on the outputs of a catastrophe model, the insurer can construct an exceedance probability (EP) curve that specifies the probabilities that a certain level of losses will be exceeded in a specific location (or its entire portfolio) over a specific period of time (e.g., one year, 10 years, etc). These losses can be measured in terms of dollars of damage, fatalities, illness or some other unit of analysis.

Suppose one were interested in constructing an EP curve for an insurer with a given portfolio of insurance policies covering wind damage from hurricanes in a southeastern U.S. coastal community. One would combine the set of events that could produce a given dollar loss and then determine the resulting probabilities of exceeding losses of different dollar magnitudes. Based on these estimates, one can construct a mean EP curve, such as the one depicted in Figure 4. The $\mathrm{x}$-axis measures the loss to insurer in dollars and the y-axis depicts the probability that losses will exceed a particular level. Suppose the insurer focuses on a specific loss $L_{i}$. One can see from Figure 4 that the likelihood that insured losses exceed $L_{i}$ is given by $p_{i}$.

An insurer utilizes its EP curve for determining how many structures it will want to include in its portfolio given that there is some chance that there will be hurricanes causing damage to some subset of its policies during a given year. More specifically, if the insurer wanted to reduce the probability of a loss from hurricanes that exceeds $L_{i}$ to be less than $p_{i}$ it will have to determine what strategy to follow. The insurer could reduce the number of policies in force for these hazards, increase the premium or decide not to offer this type of coverage at all. 


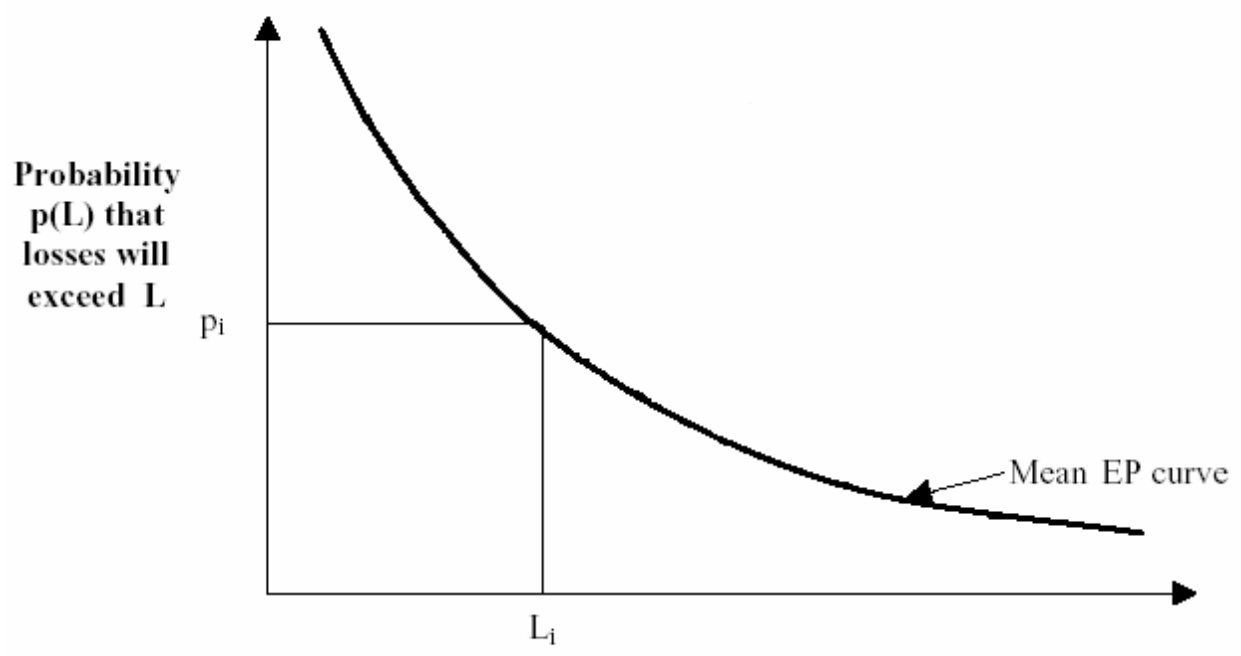

Loss, L (in Dollars)

Figure 4. Sample Mean Exceedance Probability Curve

Government agencies may want to use EP curves for estimating the likelihood that losses to specific communities or regions of the country from natural disasters in the coming year will exceed certain levels in order to determine the chances that it will have to provide disaster assistance to these stricken areas. At the start of the hurricane season in 2004, Florida could have used an EP curve to estimate the likelihood of insured damage exceeding \$23 billion. Although this probability would have been extremely low, we now know that a confluence of major events (i.e. Hurricanes Charley, Frances, Ivan and Jeanne) produced an outcome that actually exceeded this dollar value. This raises the question of the degree of confidence around the construction of a specific EP curve.

The uncertainty associated with the probability of an event occurring and the magnitude of dollar losses of an EP curve is reflected in the 5 percent and 95 percent confidence interval curves in Figure 5. The curve depicting the uncertainty in the loss shows the range of values, $L_{i}{ }^{05}$ and $L_{i}{ }^{95}$ that losses can take for a given mean value, $L_{i}$, so that there is a 95 percent chance that the loss will be exceeded with probability $p_{i}$. In a similar vein one can determine the range of probabilities, $p_{i}{ }^{.05}$ and $p_{i}{ }^{95}$ so that there is 95 percent certainty that losses will exceed $L_{i}$. For low probability-high consequence risks, the spread between the 5 percent and 95 percent confidence intervals depicted in Figure 5 that show the degree of indeterminacy of these events can be significant. 


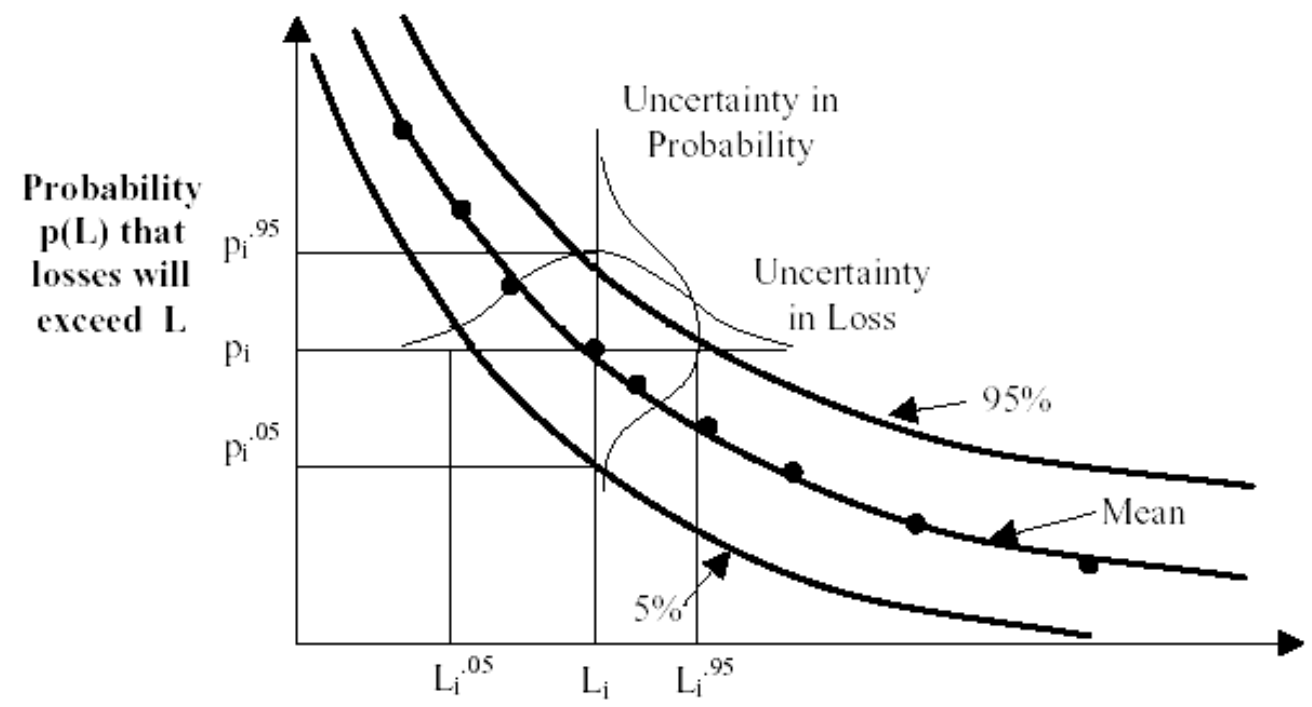

Loss, L (in Dollars)

Figure 5. Confidence Intervals for a Mean Exceedance Probability (EP) Curve

The EP curve serves as an important element for evaluating risk management tools. It puts pressure on experts to make explicit the assumptions on which they are basing their estimates of the likelihood of certain events occurring and the resulting consequences. A key question that needs to be addressed in constructing an EP curve is the degree of uncertainty regarding both probability and outcomes. A more specific EP curve (e.g. the exposure of a given insurer in a specific city versus the exposure of the insurance industry for the entire southeastern U.S. coast) the higher the uncertainty associated with the estimates is likely to be.

Extreme events, such as natural disasters, pose a set of challenging problems for insurers because they involve potentially high losses that are extremely uncertain. In the case of natural disasters, Figure 6 illustrates the total number of loss events from 1950 to 2000 in the United States for three prevalent hazards: earthquakes, floods and hurricanes. Events were selected that had at least $\$ 1$ billion of economic damage and/or over 50 deaths (American Re, 2002) ${ }^{37}$. Looking across all the disasters of a particular type (earthquake, hurricane, or flood), for this 50year period, the median loss is low while the maximum loss is very high. Given this wide variation in loss distribution, it is not surprising that insurers are concerned about the uncertainty of the loss in estimating premiums, or even providing any coverage in certain hazard prone areas.

\footnotetext{
${ }^{37}$ American Re, Topics: Annual Review of North American Natural Catastrophes 2001 (2002).
} 


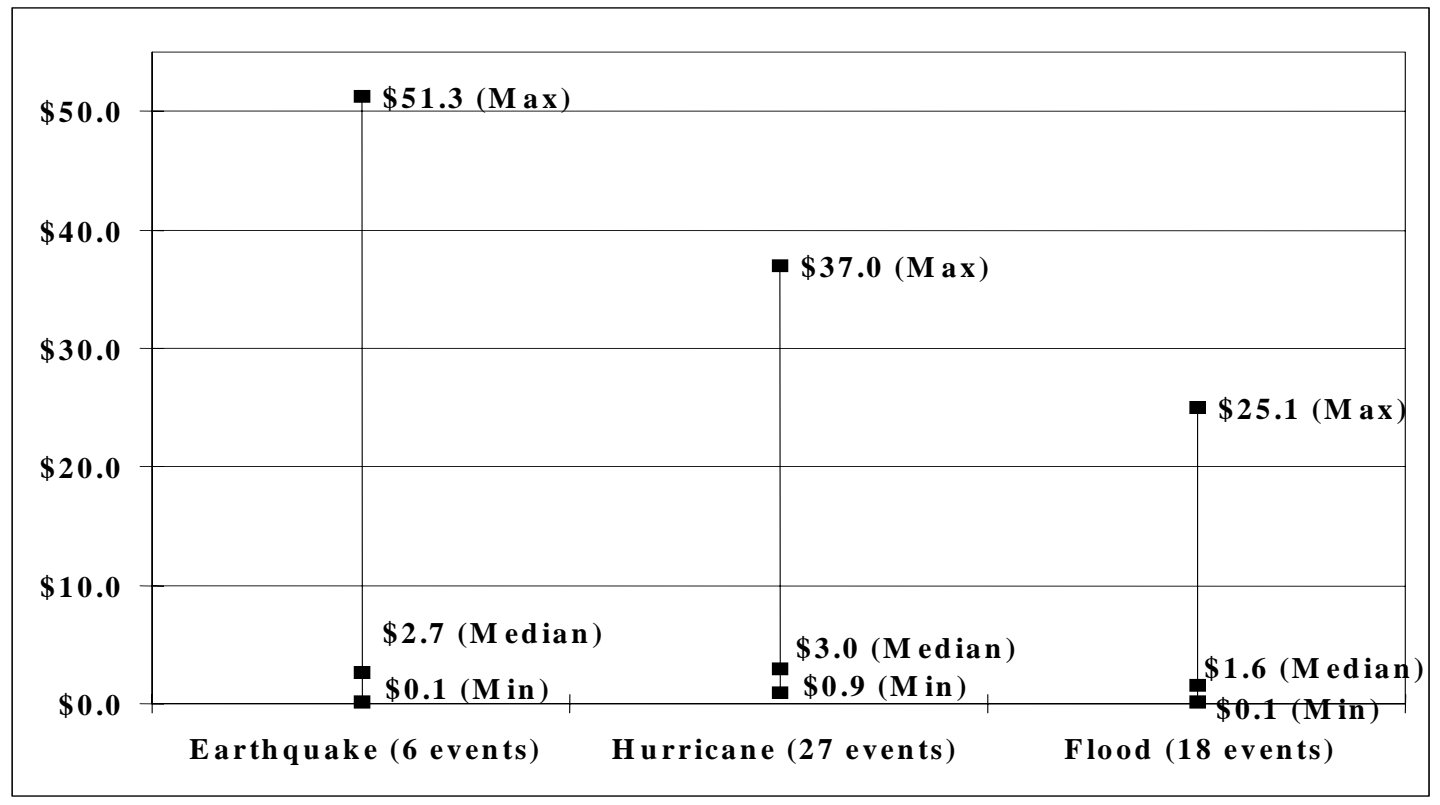

Figure 6. Historical economic losses in \$ millions versus type of significant U.S. natural disaster for the 50 year period from 1950 to 2000.

In the case of natural disasters, the future is likely to be different than the past. As discussed earlier in the paper, among the 20 most costly insurance losses from catastrophes between 1970 and 2005, ten occurred during the last five years. The 2004 and 2005 seasons have already dramatically changed the upper limits in Figure 6. Hurricane Katrina is said to have caused between $\$ 150$ billion and $\$ 170$ billion in economic losses, more than four times higher than the most costly hurricane between 1950 and 2000.

\section{Determining Whether to Provide Coverage}

Based on their knowledge of likelihood and outcome, an insurer still has to make a decision as to whether to cover the risk (unless they are required to do so by law). In his study on insurers' decision rules as to when they would market coverage for a specific risk, Stone (1973) ${ }^{38}$ develops a model whereby firms maximize expected profits subject to satisfying a constraint related to the survival of the firm ${ }^{39}$. An insurer satisfies its survival constraint by choosing a portfolio of risks with an overall expected probability of total claims payments greater than some

\footnotetext{
38 Stone, J., “A Theory of Capacity and the Insurance of Catastrophic Risks: Part I and Part II”, 40, JoURNAL OF RISK AND INSURANCE at 231(Part I) and 339 (Part II) (1973).

39 Stone also introduces a constraint regarding the stability of the insurer's operation. However, insurers have traditionally not focused on this constraint in dealing with catastrophic risks.
} 
predetermined amount $\left(L^{*}\right)$ that is less than some threshold probability, $p_{1}$. This threshold probability reflects the tradeoff between the expected benefits of another policy and the costs to the firm of a catastrophic loss that reduces the insurer's surplus by $L^{*}$ or more. This threshold probability does not necessarily correspond to what would be efficient for society. The value of $L^{*}$ is determined by an insurer's concern with insolvency and/or a sufficiently large loss in surplus that will lead a rating agency to downgrade its credit rating.

A simple example illustrates how an insurer would utilize its survival constraint to determine whether a particular portfolio of risks is insurable with respect to hurricanes. Assume that all homes in a hurricane-prone area are identical and equally resistant to damage such that the insurance premium, $z$, is the same for each structure. Furthermore assume that an insurer has A dollars in current surplus and wants to determine the number of policies it can write and still satisfy its survival constraint. Then, the maximum number of policies, $n$, satisfying the survival constraint is given by:

$$
\text { Probability [Claims Payments } \left.\left(\mathrm{L}^{*}\right)>(\mathrm{n} \cdot \mathrm{z}+\mathrm{A})\right]<\mathrm{p}_{1}
$$

The insurer will use the survival constraint to determine the maximum number of policies it is willing to offer, with possibly an adjustment in the amount of coverage and premiums, and/or a transfer of some of the risk to others in the private sector (e.g. reinsurers or capital markets). It may also rely on state or federal programs to cover its catastrophic losses.

Following the series of natural disasters that occurred at the end of the 1980s and in the 1990s, insurers focused on the survival constraint to determine the amount of catastrophe coverage they were willing to provide because they were concerned that their aggregate exposure to a particular risk did not exceed a certain level. Rating agencies, such as A.M. Best, focused on insurers' exposure to catastrophic losses as one element in determining credit ratings, so insurers paid attention to this risk.

The insurance industry was unaware of the potential large loss they could suffer from hurricanes in Florida and earthquakes in California. More specifically, some insurers were surprised at the magnitude of their losses from the Hurricane Andrew in 1992 and the Northridge earthquake in 1994. In fact, following Hurricane Andrew many insurers only marketed coverage against wind damage in Florida because they were required to do so and state insurance pools 
were formed to limit their risk ${ }^{40}$. In California, insurers refused to renew homeowners' earthquake policies after the 1994 Northridge earthquake and the California Earthquake Authority was formed by the State of California in 1996 with funds from insurers and reinsurers ${ }^{41}$.

Setting Premiums -- If the insurer decides to offer coverage, it needs to determine a premium rate that yields a profit and satisfies its survival constraint given by (1). State regulations often limit insurers in their rate-setting process. Competition can play a role as well as to what premium can be charged in a given marketplace. Even in the absence of these influences, an insurer must consider problems associated with the ambiguity of the risk, asymmetry of information (adverse selection and moral hazard), and degree of correlation of the risk in determining what premium to charge. We will examine each of these factors in turn.

Impact of the Ambiguity of the Risk The infrequency of major catastrophes in a single location implies that the loss distribution is not well specified. The ambiguities associated with the probability of an extreme event and with the outcomes of such an event raise a number of challenges for insurers with respect to pricing their policies. As shown by a series of empirical studies, actuaries and underwriters are averse to ambiguity and want to charge much higher premiums when the likelihood and/or consequences of a risk are highly uncertain than if these components of risk are well specified.

Kunreuther et al. (1995) conducted a survey of 896 underwriters in 190 randomly chosen insurance companies to determine what premiums would be required to insure a factory against property damage from a severe earthquake ${ }^{42}$. The survey examined changes in pricing strategy as function of the degree of uncertainty in either the probability and/or loss. A probability was considered to be well-specified when there was enough historical information on an event that all experts agree that the probability of a loss is $p$. When there was wide disagreement about the

\footnotetext{
${ }^{40}$ Grace, M., Klein, R., Kleindorfer, P. and Murray, M., Catastrophe Insurance: Consumer Demand, Markets and Regulation (2003).

${ }^{41}$ Roth, R., Jr., Earthquake Insurance Protection in California, Chapter 4 in Kunreuther, H. and Roth, R., Sr. (eds.), Paying the Price: The Status and Role of Insurance Against Natural Disasters in the United States (1998).

${ }^{42}$ Kunreuther, H., Meszaros, J., Hogarth, R. and Spranca M., Ambiguity and underwriter decision processes, 26 JOURNAL OF ECONOMIC BEHAVIOUR AND ORGANIZATION at 337 (1995).
} 
estimate of $p$ among the experts, this ambiguous probability is referred to as $A p$. $L$ represents a known loss reflecting a general consensus as to what insurers' claims would likely be in the event of a disaster. When the experts' estimates range between $L_{\min }$ and $L_{\text {max }}$, this uncertain loss is denoted as UL. Combining the degree of probability and loss uncertainty leads to the four cases shown in the columns of Table 2.

To see how underwriters reacted to different situations, four scenarios were constructed as shown by the rows in Table 2. Where the risk is well-specified, the probability of the earthquake is either .01 or .005; the loss, should the event occur, is either $\$ 1$ million or $\$ 10$ million. The premium set by the underwriter is standardized at 1 for the non-ambiguous case. One can then examine how ambiguity affects pricing decisions.

Table 2 shows the ratio of the other three cases relative to the non-ambiguous case $(p, L)$ for the four different scenarios, which were distributed, randomly to underwriters in primary insurance companies. For the highly ambiguous case $(A p, U L)$, the premiums were between 1.43 to 1.77 times higher than if underwriters priced a non-ambiguous risk. The ratios for the other two cases were always above 1 , but less than the $(A p, U L)$ case. Since measuring the impact of global warming on the likelihood and consequences of weather-related catastrophes is even more ambiguous than the earthquake risk, one would expect the ratio of $(A p, U L)$ relative to $(p, L)$ to be higher if underwriters were asked the same questions for setting the corresponding premiums for these disasters.

Table 2. Ratios of Underwriters' Premiums for Ambiguous or Uncertain Earthquake Risks Relative to WellSpecified Risks*

\begin{tabular}{|c|c|c|c|c|c|}
\hline \multirow[t]{2}{*}{ Scenario } & \multicolumn{5}{|c|}{ Cases } \\
\hline & 1 & 2 & 3 & 4 & \multirow{3}{*}{$\mathrm{N}^{* *}$} \\
\hline & \multirow[t]{2}{*}{$\mathrm{p}, \mathrm{L}$} & \multicolumn{3}{|c|}{ 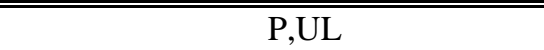 } & \\
\hline & & Ap,L & & Ap,UL & \\
\hline $\begin{array}{l}\mathrm{P}=.005 \\
\mathrm{~L}=\$ 1 \text { million }\end{array}$ & 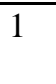 & 1.28 & 1.19 & 1.77 & 17 \\
\hline $\begin{array}{l}\mathrm{P}=.005 \\
\mathrm{~L}=\$ 10 \text { million }\end{array}$ & 1 & 1.31 & 1.29 & 1.59 & 8 \\
\hline $\begin{array}{l}\mathrm{P}=.01 \\
\mathrm{~L}=\$ 1 \text { million }\end{array}$ & 1 & 1.19 & 1.21 & 1.50 & 23 \\
\hline $\begin{array}{l}\mathrm{P}=.01 \\
\mathrm{~L}=\$ 10 \text { million }\end{array}$ & 1 & 1.38 & 1.15 & 1.43 & 6 \\
\hline
\end{tabular}

*Ratios are based on mean premiums across number of respondents for each scenario.

$* * \mathrm{~N}=$ number of respondents

Source: Adapted from Table 3 in Kunreuther et al (1995) ${ }^{43}$

\footnotetext{
${ }^{43}$ Kunreuther, H., Meszaros, J., Hogarth, R. and Spranca M., Ambiguity and underwriter decision processes, 26 JOURNAL OF ECONOMIC BEHAVIOUR AND ORGANIZATION at 337 (1995).
} 
There are other insurability issues associated with information that come from asymmetry of information between the insurers and the insured.

Adverse Selection If the insurer cannot differentiate the risks facing two groups of potential insurance buyers and each buyer knows her own risk, then the insurer is likely to suffer losses if it sets the same premium for both groups by using the entire population as a basis for this estimate. If only the highest risk group is likely to purchase coverage for that hazard and the premium is below its expected loss, the insurer will have a portfolio of "bad" risks. This situation, referred to as adverse selection, can be rectified by the insurer charging a high enough premium to cover the losses from the bad risks. In so doing, the good risks might purchase only partial protection or no insurance at all because they consider the price of coverage to be too expensive relative to their risk ${ }^{44}$.

The problem of adverse selection only emerges in unregulated markets if those considering the purchase of insurance have more accurate information on the probability of a loss than the firms selling coverage. If the policyholders and insurers both cannot distinguish their risks then coverage will be offered at a single premium based on the average risk, and both good and poor risks will want to purchase policies.

In the context of climate change, adverse selection is not likely to be a problem since there is no evidence that those at risk have an informational advantage over the insurer. In fact, the opposite might be true: if insurance companies spend a lot of resources estimating the risk, they might gain an informational advantage over their policyholders who cannot afford or want to do so. Over the past five or six years, there has been a growing literature studying the impact of insurers being more knowledgeable about the risks than the insured themselves. Research in this field reveals that insurers might want to exploit this "reverse information asymmetry", which results in low risk agents being optimally covered while high risks are not. ${ }^{45}$

Moral Hazard This refers to an increase in the expected loss (probability or amount of loss conditional on an event occurring) caused by insurance-induced changes in the behavior of the policyholder. An example of moral hazard is more careless behavior vis-à-vis natural hazards or other types of risk as a result of purchasing coverage. Providing insurance protection may lead

\footnotetext{
${ }^{44}$ For a survey of adverse selection issues, see Dionne, G., Doherty, N. and Fombaron, N., Adverse Selection in Insurance Markets, Chapter 7 in Dionne, G. (ed.) Handbook of Insurance (2000).

${ }^{45}$ D. Henriet and E. Michel-Kerjan, Optimal Risk-Sharing under Dual Asymmetry of both Information and Market Power: A Unifying Approach, Working Paper, Wharton Risk Management and Decision Processes Center (2006).
} 
the policyholder to change behavior in ways that increase the expected loss from what it would have been without coverage. If the insurer cannot predict this behavior and relies on past loss data from uninsured individuals to estimate rates, the resulting premium is likely to be too low to cover losses.

Even after the insurer is aware that people with insurance have higher losses, its inability to observe loss-enhancing behavior may create problems of moral hazard. The introduction of specific deductibles, coinsurance or upper limits on coverage can be useful tools in reduce moral hazard by encouraging insureds to engage in less risky behavior, as they know they will have to incur part of the losses from an adverse event. It is unclear whether moral hazard plays a role in the context of global climate change.

Correlated Risks For extreme events, the potential for high correlation between the risks will have an impact on the tail of the distribution. In other words, at a predefined probability $p_{i}$, the region below the EP curve is likely to expand for higher correlated risks covered by insurers. This requires additional capital for the insurer to protect itself against large losses. Even risks that are assumed to be independent, such as fire, can be highly correlated. For example, the Oakland conflagration of October 20, 1991 damaged or destroyed 3,000 structures for a total insured loss of $\$ 1.7$ billion. More recently, the fires in Southern California between October 23 and November 6 of 2003, destroyed over 750,000 acres of land and approximately 4,000 residential properties ${ }^{46}$.

Insurers normally face spatially correlated losses from large-scale natural disasters. State Farm and Allstate Insurance paid \$3.6 billion and \$2.3 billion in claims respectively in the wake of Hurricane Andrew in 1992 due to their high concentration of homeowners' policies in the Miami/Dade County area of Florida. Given this unexpectedly high loss, both companies began to reassess their strategies of providing coverage against wind damage in hurricane-prone areas. ${ }^{47}$

Hurricanes Katrina and Rita that devastated the U.S Gulf Coast in August and September 2005 impacted dramatically on several lines, including life, property damage, business interruption. Edward Liddy, chairman of Allstate, which provided insurance coverage to 350,000

\footnotetext{
${ }^{46}$ P. West, Lessons Learned from Southern California's Firestorms Released, January 23, WiLDFIRE MAGAZINE, (2004).

${ }^{47}$ E. Lecomte and K. Gahagan, Hurricane Insurance Protection in Florida, in Howard Kunreuther and Richard Roth, Sr. (eds.), Paying the Price: The Status and Role of Insurance Against Natural Disasters in the United States (1998).
} 
homeowners in Louisiana, Mississippi and Alabama, declared that "extensive flooding has complicated disaster planning ... and the higher water has essentially altered efforts to assess damage. We now have 1,100 adjusters on the ground. We have another 500 who are ready to go as soon as we can get into some of the most-devastated areas. It will be many weeks, probably months, before there are anything approaching reliable estimates”48.

\section{Other Stakeholders Affecting Insurers Decision}

Our analysis of insurability would not be complete without consider the environment in which insurers have to make decisions. There are several other important players whose actions affect insurers' decision on whether to provide coverage against certain risks, and if so how much to offer and what price to charge. We discuss the roles of five key parties: reinsurers, insurance commissioners, rating agencies, modeling firms and investors.

\section{Reinsurers}

How much coverage an insurer can provide in a certain area depends also on what portion of its exposure it can transfer to reinsurers. Reinsurers provide protection to private insurers in much the same way that insurers provide coverage to their policyholders. They charge a premium to indemnify an insurance company against a layer of catastrophic losses which the insurer would otherwise be responsible for covering. Reinsurers are also concerned with their concentration of risk and restrict their exposure in catastrophe-prone areas to keep the chances of severe losses at an acceptable level. Large reinsurers who operate worldwide can diversify their risk geographically and per line of coverage much more easily than most insurers can.

Reinsurers typically play a key role in sharing a significant portion of the insured losses with the insurers. For example, reinsurers shared about 50\% of insured losses due to Hurricane Katrina. As a result of the 2004 and 2005 hurricane seasons, the price of catastrophe reinsurance in the U.S. has significantly increased and there is considerable uncertainty as to what will be the availability of coverage and the resulting prices in the coming year. It should not come as a surprise that the two largest reinsurers in the world, Swiss Re and Munich Re, have been active in climate change research for some time now.

\footnotetext{
${ }^{48}$ T. Francis, CEO Says Allstate Adjusts Storm Plan. Interview of Edward Liddy, The WALL STREET Journal, September 5, 2005 at C1.
} 


\section{Capital Markets}

Capital markets have emerged in the 1990s as a complement to reinsurance for covering large losses from natural disasters through new financial instruments, e.g., industry loss warranties, catastrophe bonds and, more recently, sidecar reinsurers.

For example, the shortage of reinsurance following Hurricane Andrew in 1992 and the Northridge earthquake in 1994 led to higher reinsurance prices and made it possible for insurers to offer catastrophe bonds with high enough interest rates to attract capital from investors. In addition, the prospect of an investment that is uncorrelated with the stock market or general economic conditions is also attractive to capital market investors. Finally, catastrophe models have emerged as a tool for more rigorously estimating loss probabilities, so that disaster risk can be more accurately quantified than in the past, and then priced.

Since hurricane Katrina hit in 2005, there has been a significant increase in the number and volume of catastrophe bond issuances and the creation of sidecars, but the total volume of financial protection remains somewhat limited compared to what is currently provided by traditional reinsurance. Hence, there is a need to assess the constraints on the availability and volume of securities that diversify catastrophe risk and how the use of these vehicles could be expanded to augment reinsurance capacity.

\section{State Insurance Commissioners}

In the United States insurance is regulated at the state level with the principal authority residing with insurance commissioners. Domestic reinsurers are subject to solvency regulation but not to rate or policy form regulation. Solvency regulation addresses the question as to whether the insurer or reinsurer is sufficiently capitalized to fulfill its obligations if a significant event occurs and inflicts major losses on its policyholders. Insurance commissioners regard solvency as a part of their concern even if it means requiring higher premiums. On the other hand, they want insurance to be sold at economically affordable prices. In balancing the solvency and consumer protection goals, insurance regulators are concerned that rates are adequate, not excessive and not unfairly discriminatory. These terms are somewhat imprecise, so regulators have some latitude in controlling insurer behavior. 
In March 2006, the National Association of Insurance Commissioners (NAIC) established a Task Force to study how climate change may affect the availability and affordability of insurance for consumers and the financial health of insurance companies. The task force, led by Tim Wagner, director of the Nebraska Department of Insurance, and Mike Kreidler, insurance commissioner for the State of Washington, will also consider actions that would enable state regulators and insurers working together to mitigate risks associated with it ${ }^{49}$.

\section{Modeling firms}

As discussed above, many insurance and reinsurance companies have turned to firms specialized in the business of modeling catastrophe risks to assist them in determining how much coverage to offer and what premiums to charge for losses from natural disasters. Over the past ten years, these companies have become important players in the field of catastrophe insurance and reinsurance. As a result of the 2005 hurricane season, Risk Management Solutions (RMS), one of the leading catastrophe modeling firms, announced in March 2006 that changes of hurricane landfall frequencies in its new model will increase its estimates of average annual insurance losses by 45 percent across the Gulf Coast, Florida, and the Southeast, and by 25-30 percent in the Mid-Atlantic and Northeast coastal regions relative to those derived using longterm 1900-2005 historical average hurricane frequencies (Risk Management Solutions, 2006) ${ }^{50}$.

This revised view of the hurricane risk is driven by an increase of more than 30 percent in the modeled frequency of major hurricanes (Category 3-5 on the Saffir-Simpson scale) in the Atlantic basin that are expected to persist for at least the next five years. How the insurance market and regulators will react to this new dimension is still an open issue and will certainly depend on estimates by the other two leading modeling firms, AIR Worldwide and EQECAT, both of whom have adjusted their estimates upward by a much smaller percentage than has RMS. Both these firms offer a near term model that reflects higher rates due to current warming of sea surface temperatures that is likely to cause an increase in hurricane activity (see our discussion in Section 3).

\section{Rating Agencies}

\footnotetext{
49 The Insurance Journal, National News: Regulators Establish Task Force on Climate Change, March $14,2006$.

${ }^{50}$ Risk Management Solutions, Press Release: New RMS View of U.S. Hurricane Activity Rates Increases Losses by 40\% in Florida and Gulf Coast, March 22, 2006.
} 
Rating agencies, such as A.M. Best, Standard \& Poor's, Moody's and Fitch, provide independent evaluations of insurers' and reinsurers' financial stability and their ability to meet their obligations to policyholders. The rating assigned to an insurer or reinsurer has significant consequences on the premiums it can set and its ability to raise capital. For example, many large publicly trade companies have requirements that they only deal with insurers that have a rating above a certain minimum level. Similarly, insurers are less willing to cede their risks to a poorly rated reinsurer. A low rating has an impact on the premium an insurer or reinsurer can charge or the amount of coverage it is able to sell. It is also likely to have a negative effect on the share price of publicly traded firms.

To illustrate how ratings are determined consider A.M. Best. It undertakes a quantitative analysis of an insurer's balance sheet strength, operating performance and business profile. Evaluation of catastrophe exposure plays a significant role in the determination of ratings, as these are events that could threaten the solvency of a company. Projected losses of disasters occurring at specified return periods (a 100-year windstorm/hurricane or a 250-year earthquake) and the associated reinsurance programs to cover them are two important components of the rating questionnaires that insurers are required to complete.

For several years now, A.M. Best has been requesting such information for natural disasters. Their approach has been an important step forward in the incorporation of catastrophe risk into an insurer's capital adequacy requirements. Up until recently the rating agency has been including probable maximum loss (PML) for only one of these severe events (100-year windstorm / 250-year earthquake, depending on the nature of the risk the insurer was mainly exposed to) in its calculation of a company's risk-adjusted capitalization. In 2006 A.M. Best introduced a second event as an additional stress test. The PML used for the second event is the same as the first event in the case of hurricane (a 1-in-100 year event; the occurrence of one hurricane is considered to be independent of the other one). If the main exposure facing the insurer is an earthquake, the second event is reduced from a 1-in-250 year event to a 1-in-100 year event (A.M. Best, 2006) ${ }^{51}$.

\section{Investors}

${ }^{51}$ A.M. Best, Methodology: Catastrophe Analysis in AM Best Ratings (2006). 
The large increase in insured losses in the last ten years, the changes in the catastrophe risk models in 2006, and the requirement by rating agencies to include a second stress test have important consequences for determining the insurability of hurricanes and other natural disasters. Moreover, recent catastrophes have revealed a much higher degree of volatility for any given portfolio than in the past. This will have also an impact on the cost of capital provided to insurers and reinsurers. With higher volatility investors will demand a higher return on equity. This requires insurers to restrict their coverage, charge higher premiums and/or improve their exposure management.

\section{Another Uncertainty facing Insurers: Liability from Climate Change}

We now turn to the following related issue facing insurers---their potential liability for losses claimed to have been due to climate change induced by their policyholders (i.e. firms). For example, the issue could arise from legal actions against executives for failure to report to their shareholders some of the climate-related risks faced by the company. We first address the liability question by examining the role that tort law plays in holding individuals accountable for damage and discuss the current debate regarding its applicability to climate change. We then turn to the role of Directors and Officers' liability insurance (D\&O) in the context of climate change risks. The section concludes with a brief discussion of how companies can be encouraged by insurance to mitigate future damage from climate change.

The first carbon dioxide lawsuit in the U.S. was filed in July 2004. Eight states and New York City sued five large electricity utilities that are the country's biggest emitters of carbon dioxide and which operate 174 power plants in 20 states. Although the case was dismissed (some states may appeal), the use of liability as a wedge for Climate Policy Action may play a greater role in coming years. If this case had not been dismissed then the insurers of the five utilities may have been financially responsible for the damage settlement and the court costs.

One of the open issues is whether the tort law is appropriate for holding firms financially accountable for specific losses suffered by others because their actions were partially responsible 
for global warming. As Faure and Grimaud (2003) $)^{52}$ note the first goal of tort law is to minimize the sum of accident costs and the costs of accident avoidance---in other words to minimize the social costs of accidents.

The appropriate strategy to follow has been laid out by Shavell $(1993)^{53}$ in a simple model where the objective is to determine the level of care $(x)$ of a potential victim $A$ and the level of care $(y)$ of a potential injurer (firm) $B$ that minimizes total expected cost $[C(x, y)]$ where

$$
\begin{gathered}
C(x, y)=p(x, y) L+A(x)+B(y) \\
p(x, y)=\text { probability of an accident } \\
L=\text { the magnitude of the resulting loss }
\end{gathered}
$$

This model is appropriate for cases where both $p(x, y)$ and $L$ are well-defined. However, with respect to global climate change it is difficult to characterize these parameters based on our current state of scientific knowledge.

Despite this element of uncertainty, litigation has emerged re global warming as noted above with respect the carbon dioxide lawsuit against electrical utilities. In a case Massachusetts vs. Environmental Protection Agency (EPA), the state (Plaintiff) challenged the denial of a petition asking the EPA to regulate $\mathrm{CO}_{2}$ and other greenhouse gas emissions from new motor vehicles. There was controversy among the three judges so that a decision has not yet been finalized. Judge Randolph ruled for the EPA given uncertainty with respect to the relationship between motor vehicle emissions, greenhouse gas and climate change. Judge Tatel, on the other hand, found that the plaintiff had standing because a rise in sea level would hurt Massachusetts, and that sea level rises were caused by human emissions. The third judge, Judge Sentell, felt that causation was uncertain but he couldn't review EPA's position without first giving Massachusetts standing ${ }^{54}$.

In a similar vein inhabitants of Pacific Island nations claim that rising sea levels due to climate change have submerged their homes. They have announced intentions to commence litigation against major sources of $\mathrm{CO}_{2}$ under the Alien Tort Claims Act where non-citizens can

\footnotetext{
${ }^{52}$ M. Faure and D. Grimeaud, Principles of Liability: A Theoretical Framework in M. Faure and D. Grimeaud (eds.), Deterrence, Insurability and Compensation in Environmental Liability (2003).

${ }^{53}$ Shavell, Steven, The Optimal Structure of Law Enforcement, 36 JouRNAL OF LAW AND ECONOMICS at 255 (1993).

${ }^{54}$ Farber, D., Uncertainty as a Basis for Standing, 33 HofsTRA LAW REVIEW at 1123 (2005).
} 
bring suits in federal court for violating international law. Their claim is that there are costs for relocating populations due to higher sea levels ${ }^{55}$. Such litigation would face enormous hurdles given the difficulty in establishing specific causal links between activity of a corporation and harm. An individual producer's liability is generally non-quantifiable and may be largely dependent on external factors outside of the producer's control ${ }^{56}$.

\section{Compensation Based on Proportional Liability}

Climate change is subject to fluctuations in frequency and severity so that it is difficult to differentiate a particular pattern in temperature change or sea level caused by anthropogenic climate change from one caused by natural variability ${ }^{57}$. If it is impossible to attribute a specific event to climate change, one may still be able to compensate individuals on the basis of increased likelihood of the event due to global warming.

Oxford University's Allen has taken this tack in dealing with the causality issue as it relates to climate change. He considers the case of flooding in Southern England in January 2003 where there was a suit by disaster victims claiming that it was due to past greenhouse gas emissions. The Third Assessment Report of the Intergovernmental Panel on Climate Change is cited, which concluded that "most of the observed warming over the past 50 years is likely to have been due to the increase in greenhouse gas concentrations”. Allen proposes payments based on a form of proportional liability where the emitter is responsible for the increased risk of flooding due to the greenhouse gases it produced ${ }^{58}$.

It is interesting to note that this approach has features similar to the assigned shares model developed 20 years ago by Lagakos and Mosteller ${ }^{59}$ for providing compensation to cancer victims where the cause of the disease was difficult to determine. In their model two subgroups of individuals were compared---one exposed to a specific dose of radiation and another that was not. It is then possible to compute the ratio of the number of excess cancer cases in the exposed

\footnotetext{
${ }^{55}$ Healy, J. K. and J. M. Tapick, Climate Change: It's Not Just a Policy Issue for Corporate Council - It's a Legal Problem, 29 COLUMBIA JOURNAL OF ENVIRONMENTAL LAW at 89 (2004).

${ }^{56}$ Hancock, E., Red Dawn, Blue Thunder, Purple Rain: Corporate Risk of Liability for Global Climate Change and the SEC Disclosure Dilemma, 27 (2) GEORGETOWN INTERNATIONAL ENVIRONMENTAL LAW REVIEW (2005).

${ }^{57}$ Grossman, D., Warming Up to a Not-So-Radical Idea: Tort-Based Climate Change Litigation, 28 ColumBIA JOURNAL OF ENVIRONMENTAL LAW at 1 (2003).

${ }^{58}$ Allen, M., Liability for Climate Change, 421 NATURE at 891 (2003); Allen, M and R. Lord, The Blame Game, 432 NATURE at 551 (2004).

${ }^{59}$ Lagakos, S and Mosteller, F., Assigned Shares in Compensation for Radiation-Related Cancers, 6 RISK ANALYSIS at 345 (1986).
} 
subgroup over the number of cancer cases in the exposed subgroup. This fraction is designated as the assigned share and represents the probability that the cancer was caused by the radiation dose. For instance, if there is a $20 \%$ chance that a randomly selected individual from the exposed group will have had his cancer caused by his previous radiation exposure, then the firm that exposed the individual to this radiation dose would pay $20 \%$ of the amount of compensation normally given to such a person who contracts cancer.

With respect to global climate change suppose that scientists believe that global warming due to greenhouse gas emissions has increased the frequency of hurricanes in a region by $40 \%$ over what it otherwise would have been. Then if the property damage from a hurricane in Florida was $\$ 1$ billion dollars then according this proportional probabilistic liability approach, those whose actions have produced greenhouse gas emissions would be responsible for paying a portion of the $40 \%$ of the losses.

This approach has theoretical merit but faces practical difficulties on several grounds. First it will be difficult to gain any agreement by scientists on the extent to which global warming has increased the likelihood of natural disasters occurring. Quantifying the link between carbon dioxide emission and an increase sea surface temperature is not easy. Furthermore, as we discussed earlier in this paper, there is a growing debate about the link between sea surface temperature and increased frequency and/or severity of hurricanes. Second, it will be extremely hard to determine who is responsible for increasing greenhouse gases unless one has some yardstick for measuring the amount in the atmosphere.

On the other hand, polluters bear some responsibility for their impact on climate change. Based on the current state of knowledge, the use of economic tools such as tradable emissions permits would certainly help in that quantification process. But here again, as emissions are typically global, another challenge would be to assure that all emitters are paying for their portion of the $40 \%$ of the loss.

In the end, we might also see some judges arguing that if a specific industry is responsible for a large majority of the emission in a country and is financially strong (e.g., electricity sector in the US), then they should be held responsible for the consequences of global warming and pay for it. How much responsibility remains an open question.

Perhaps of even greater importance is that the threat of global warming class action suits might be sufficient to encourage firms who are large emitters to restrict their future pollution to 
avoid being sued and for insurers to refuse to provide coverage unless the firms undertook such measures.

There are precedents in other areas that may provide some guidance as to what may happen in the future. As Hersch and Viscusi note in their article in this issue, "while environmental litigation of this type is unprecedented, the cigarette cases were novel as well at the time. The cigarette litigation did not establish legal precedents because the cases were settled without any court verdicts, but the threat of the suits was sufficiently real that it led to damages payments of close to $\$ 250$ billion” ${ }^{\text {. }}$.

\section{Impact of Climate Change on Directors and Officers Coverage (D\&O)}

We now turn to another liability challenge that insurers will have to deal with in the coming years: possible legal actions against executives of companies for failure to report to their shareholders some of the climate-related risks faced by the company. If such firms have Directors and Officers (D\&O) coverage these individuals may be covered by this insurance should they be sued for wrongful acts committed in their role as company officers. Directors and officers must act with due diligence in carrying out their responsibilities and can be held personally liable if their actions result in a loss to the corporation or its shareholders. Anyone with an interest in a corporation, shareholders and stakeholders alike, can file a claim if they feel wronged by corporate actions. These claims can be costly, even if they are not considered valid, due to the large expenses associated with any court case which the insurer normally covers.

The impact of court cases on an insurer providing D\&O coverage to a firm can be better appreciated with respect to federal requirements for financial reporting of publicly traded corporations. The financial disclosure of any such corporation can be questioned by its shareholders who can decide to file a class action lawsuit. Beyond the corporation itself, the defendants in these cases are likely to be the board of directors and other members of the senior management. Should this happen, these directors and officers would quite understandably turn to the firm for indemnification. Corporations are permitted to indemnify officers and directors for virtually any act undertaken in good faith or with the belief that it was in the best interest of the

\footnotetext{
${ }^{60}$ Hersch, J. and K. Viscusi, Allocating Responsibility for the Failure of Global Warming Policies, Paper Prepared for University of Pennsylvania Law Review Conference on Climate Change, November 16-17, 2006.
} 
corporation. To manage this financial exposure, and also reassure their board, companies often purchase D\&O coverage ${ }^{61}$.

The Sarbanes-Oxley Act passed by Congress on July 30, 2002 requires directors and officers of a firm to report its environment liabilities to the Securities and Exchange Commission (SEC). In this spirit shareholders in a number of firms heavily involved with fossil fuels, as well as other firms whose value might be held responsible for contributing to global warming through their $\mathrm{CO}_{2}$ emissions, are pressuring companies to disclose how global warming could impact their business. As the debate on climate change intensifies, there is a risk that the directors and officers of these firms will be sued for failing to exercise their fiduciary duty toward their shareholders in the event that they do not taken actions to prepare for contingencies which may arise as a result of climate change.

In April 2004, a group of 13 public pension funds managing over $\$ 800$ billion in assets wrote a letter to then-SEC Chair William Donaldson asking him to clarify that climate change is indeed a material risk requiring disclosure on security filings and to "strengthen current disclosure requirements, for example, by providing interpretive guidance on the materiality of risks posed by climate change”. More recently, in June 2006, this now enlarged group of investors (50 members of the Investor Network on Climate Risk (INCR), representing nearly \$3 trillion in assets) reiterated the demand to the new SEC Chairman. As of today the SEC has not finalized rules regarding disclosure specifically on climate change-related risks.

In May 2005, a group of 14 leading investors and other organizations worldwide launched a new effort to improve corporate disclosure of the risks and opportunities posed by global climate change - the Climate Risk Disclosure Initiative. In October 2006, they released the Global Framework for Climate Risk Disclosure to provide specific guidance to companies regarding the information they provide to investors on the financial risks posed by climate change. ${ }^{62}$

In this context, it might be increasingly difficult for any publicly traded company not to seriously consider how climate change will affect its operation and financial results, and to report these as part of environment liabilities in their annual SEC fillings. A recent review of climate change reporting in the SEC filings of automobile, manufacturing, integrated oil \& gas,

\footnotetext{
${ }^{61}$ The two largest insurance companies in the US D\&O market are Chubb and AIG.

${ }^{62}$ The framework is available at: http://www.ceres.org/pub/docs/Framework.pdf
} 
insurance, petrochemicals, and utilities companies indicates that over the past five years, climate reporting has steadily increased in quality and has also doubled in number. According to the report, the 26 electric utilities sector all reported on climate risk, five years ago, but only half of the electric utilities offered climate reporting to shareholders. Only 6 of the 23 automobile companies and only 3 of the largest 27 property-casualty insurers in the U.S. surveyed for SEC climate disclosure in 2005 had reported any climate change risk in their annual filings ${ }^{63}$.

In the light of their cautious effort to exclude most liability exposure associated with pollution since 1985, one can anticipate that insurance companies providing D\&O would resist coverage for claims in which an insured failed to adequately disclose environment liability on financial statements or has not maintained appropriate control of how the company has managed its environmental risks, including those related to climate change ${ }^{64}$.

For example, Swiss Re, a large player in D\&O reinsurance, is treating climate change seriously in its dealings with corporations. According to Ivo Menzinger, Head of Sustainability and Emerging Risk Management at Swiss Re:

If the risk to be insured in our Directors and Officers insurance business for Large Corporate Risks has a potential carbon exposure, then we investigate how the company manages this aspect of its business operations. This is primarily done through analyzing returns made to the annual Carbon Disclosure Project survey of large corporations. However, if there is insufficient information from this source we would request details from the company concerned directly. This, together with other underwriting relevant information, flows into the decision about what coverage to offer and the pricing of the product. This process has been in place since $2003 .{ }^{65}$

According to a recent report by the insurance broker Marsh, insurers are becoming more concerned about their client's potential exposure to liability risk associated with climate change. Among questions that insurers would typically ask their clients with respect to assessing climate change and D\&O risk are: Does your company allocate responsibility for the management of climate-related risks? If so, how does it do so? Is there a committee of independent board members addressing the issues? What progress, if any, has a company made in quantifying, disclosing, and/or reporting its emissions profile? How well has a company planned for future

\footnotetext{
${ }^{63}$ Friends of Earth, Fifth Survey of Climate Change Disclosure in SEC Filings of Automobile, Insurance, Oil \& Gas, Petrochemical, and Utilities Companies, October 2006.

${ }^{64} \mathrm{~K}$, Anderson and D. Ferrera, Disclosing Environmental Liabilities. Director, Officer and Insurance Issues, 16 ENVIRONMENTAL CLAIMS JOURNAL at 3 (2004).

${ }^{65}$ Personal communication with Andreas Spiegel of Swiss Re, November 23 and 24, 2006.
} 
regulatory scenarios? ${ }^{66}$ Corporate directors have the duty to provide "good and prudent management” to the corporations they serve. Liability could arise from inaction of a corporate board where prudence dictates that action be taken ${ }^{67}$.

\section{Mitigation of Future Damage from Climate Change}

What can companies do to manage their climate change risks today? Plaintiffs are on much more solid ground by making claims based on present costs of preventing future harms than on recovering future damage from sea level rise. The general tort rule is that plaintiffs harmed by defendants are entitled to recover their reasonable expenditures needed to abate, mitigate or prevent future recurrences of harms. Courts have held that plaintiffs can recover from defendants their reasonable expenditures for erecting walls to keep water off their property ${ }^{68}$.

Insurance can play a key role in encouraging mitigation for actions that reduce the impact of climate change in the future. For example, Fireman's Fund Insurance Company is providing $5 \%$ rate credits to building owners who utilize solar panels, green roofs and recycled water supply systems because they are less prone to water damage, electrical fires and or full loss due to fire. For a 1-2\% premium Fireman's Fund would replace damaged systems with upgraded green products such as an energy star compliant roof to make it more energy efficient. Today Travelers offers a $20 \%$ discount on auto insurance to drivers of hybrid-electric vehicles ${ }^{69}$. American International Group (AIG) is also actively seeking to incorporate environmental and climate change considerations across its businesses, focusing on the development of products and services to help AIG and its clients respond to the worldwide drive to cut greenhouse gas emissions.

Mills and Lecomte ${ }^{70}$ point out that the U.S. Department of Energy catalogued 80 technologies and practices that can lower greenhouse gas emissions while reducing the risk of property damage from mechanical equipment breakdown, professional liability, builders’ risk,

\footnotetext{
${ }^{66}$ Marsh, Risk Alert-Climate Change: Business Risk and Solutions (2006).

${ }^{67}$ Healy, J. and J. Tapick, Climate Change: It's Not Just a Policy Issue for Corporate Council - It's a Legal Problem, 29 COLUMBIA JoURNAL OF ENVIRONMENTAL LAW, at 89 (2004).

${ }^{68}$ Grossman, D., Warming Up to a Not-So-Radical Idea: Tort-Based Climate Change Litigation, 28 ColumBIA JOURNAL OF ENVIRONMENTAL LAW, at 1 (2003).

${ }^{69}$ Allianz Group and World Wildlife Fund, Climate Change and Insurance: An Agenda for Action in the United States (2006).

${ }^{70}$ E. Mills and E. Lecomte, From Risk To Opportunity: How Insurers Can Proactively and Profitably Manage Climate Change, CERES (2006).
} 
business interruption and occupational health and safety. For example, one can eliminate fire hazards with energy efficient lighting solutions that give off less heat. By adopting facilityintegrated solar power systems, a firm can avert business interruption following outages on its electricity grid. Energy efficient windows can reduce energy losses by half or more and are more resistant to breakage by windstorms.

Green buildings may reduce losses from disasters as illustrated by Harmony Resort on St. John’s island which weathered Hurricanes Marilyn, Bertha, Georges and Lenny with no loss of power or hot water (due to solar energy) while operations of other facilities on the island were disrupted for weeks or months.

\section{Summary and Conclusions}

Despite the overwhelming scientific evidence that global warming is real, there is still considerable uncertainty as to its impact on weather-related disasters such as hurricanes, typhoons and floods. A look at the data on past losses from large-scale natural disasters indicates that many of the most costly events ever have occurred in recent years. There are several causes of this increased damage, notably the large-scale development in coastal areas of the United States. There has also been a lively debate by the scientists as to whether warming sea surface temperatures are a cause of the increased intensity and frequency of hurricanes. Today some insurers feel that the risks from hurricanes and other weather-related events are uninsurable by the private sector alone due to the large catastrophic losses of recent years and the impact of global warming on weather patterns.

Extreme events pose challenges for insurers because there is considerable ambiguity associated with the probability of an event occurring and the insurers' losses are often highly correlated. Catastrophe models and exceedance probability (EP) curves are useful decision aids for determining whether extreme events, such as natural disasters, are insurable risks. Given the limited historical data on these low probability events it is necessary to supplement this information with scientific models. One also needs to recognize that even after utilizing the outputs from catastrophic models there is considerable uncertainty in the estimates of the likelihood and consequences of specific events.

Based on a thorough study of the insurance claims from the 2004/2005 hurricanes that hit Florida and other Gulf Coast states, modeling firms have revised the underlying assumptions 
used to estimate the economic damage and insured losses from future catastrophes. With these new models, the same insurance portfolio today would be considered much more risky than it was a year ago. Rating agencies have also modified their rating methodologies in the past year. In addition, investors are now requiring a higher return on equity from insurers and reinsurers because of the perceived increased volatility of their portfolios. These other stakeholders have forced insurers to focusing attention on their underwriting decisions in risky areas and improve their exposure management strategy.

In addition there is a growing concern that lawsuits may be filed against firms for not taking appropriate action to reduce their greenhouse gas emissions or other pollutants that could cause global warming. We expect that insurers will be more concerned with providing Directors and Officers liability coverage to firms that they believe are not behaving responsibly in this area. On a more positive note, some insurers are encouraging firms to take positive measures to reduce climate change that also have short-run benefits with respect to mitigating damage against disaster by providing them with premium discounts.

A better understanding and quantification of the different drivers of the radical increase of economic losses due to major catastrophes in the last few years will be critical to define better strategies for private companies and implement more effective public policies to deal with future disasters (e.g., land use regulation, mitigation standards, etc). To help in that process, the insurance industry, partnering with government and international organizations (OECD, United Nations, World Meteorological Organization, World Health Organization, and World Bank, among others) might develop standardized data collection process at a more granular level than what is currently done ${ }^{71}$. These datasets should be made available to the public as well as to the research community.

Today, data collection methods differ from one country to another and the quality of these data is heterogeneous. At least two standardized international data bases should be developed: historical loss data for all type and size of disasters ${ }^{72}$, and data on insurance market penetration (who is and is not covered?) ${ }^{73}$. These data bases are likely to suggest ways that

\footnotetext{
${ }^{71}$ For a discussion on the data quality challenge, see recent contributions in P. Höppe and R. Pielke (eds.), Report of the Workshop on Climate Change and Disaster Losses, May 25-26 (2006).

${ }^{72}$ Swiss Re, Munich Re, and Leuven University have developed time series on some disaster data, but they differ in their scope and are usually not public information.

${ }^{73}$ This second type of data is likely to be a real challenge as today insurers do not make publicly available specific information as to the extent to which they provide coverage in hazard-prone areas (price, deductible and limit
} 
insurance coupled with other policy tools can reduce the risks associated with climate change while providing the financial resources to aid the recovery process when the next large-scale disaster occurs.

If insurers and reinsurers conclude that some climate-related risks have a high enough potential for causing catastrophic losses in specific areas they will not want to continue to offer coverage unless required by law. This raises the following policy questions that go beyond the scope of this paper: Should insurance be required in certain high hazard-prone areas? If so, will the private sector be able to provide this coverage alone or will some type of public-private partnership be necessary? Should land use regulation restrict new construction in high hazard prone areas? Can one design better building codes that are well-enforced? There is also the equity issue: How should we deal with individuals who have been living in high hazard areas for some time but cannot afford to pay for higher insurance premiums if rates reflect the actual risk? These and other questions are currently being addressed in a complementary study undertaken by the Wharton Risk Center in conjunction with Georgia State University and the Insurance Information Institute and in partnership with over 15 large insurers, reinsurers, their trade associations and other stakeholders from the private and public sectors interested in these critical issues.

associated with those policies), nor how much reinsurance they purchase. The risk for the insurance industry, however, is that without these granular data to explain new challenges for insurability of catastrophes in specific regions, many policymakers will continue to view insurance from a global perspective rather than focusing on specific risks. Given the $\$ 300$ billion surplus registered by this industry in 2004 for the U.S. alone, they might contend that with this available capital the industry can handle very large catastrophes. Such a statement was made recently by the U.S. Congressional Budget Office regarding terrorism risk; U.S. GAO, Catastrophe Risk, U.S. and European Approaches to Insure Natural Catastrophe and Terrorism Risks, Appendix III, GAO-05-199 (2005). Rather than attributing their 2005 record profit (even after accounting for losses due to 2005 major hurricanes), to much improved exposure management in the last 10 years, these record gains have reinforced the "they can pay for it” argument. 